\title{
Microbial Fibrinolytic Enzymes as Anti-Thrombotics: Production, Characterisation and Prodigious Biopharmaceutical Applications
}

\author{
Chhavi Sharma ${ }^{1}$, Alexander Osmolovskiy ${ }^{2, * \mathbb{D}}$ and Rajni Singh ${ }^{1, *}$ \\ 1 Amity Institute of Microbial Technology, Amity University Uttar Pradesh, Noida 201313, India; \\ sharmachhavi27@gmail.com \\ 2 Department of Microbiology, Faculty of Biology, Lomonosov Moscow State University, \\ 119991 Moscow, Russia \\ * Correspondence: aosmol@mail.ru (A.O.); rsingh3@amity.edu (R.S.); Tel.: +91-120-4392900 (R.S.)
}

check for updates

Citation: Sharma, C.;

Osmolovskiy, A.; Singh, R. Microbial

Fibrinolytic Enzymes as

Anti-Thrombotics: Production,

Characterisation and Prodigious

Biopharmaceutical Applications.

Pharmaceutics 2021, 13, 1880.

https://doi.org/10.3390/

pharmaceutics 13111880

Academic Editor: Hwankyu Lee

Received: 24 August 2021

Accepted: 29 October 2021

Published: 5 November 2021

Publisher's Note: MDPI stays neutral with regard to jurisdictional claims in published maps and institutional affiliations.

Copyright: (c) 2021 by the authors. Licensee MDPI, Basel, Switzerland. This article is an open access article distributed under the terms and conditions of the Creative Commons Attribution (CC BY) license (https:// creativecommons.org/licenses/by/ $4.0 /)$.

\begin{abstract}
Cardiac disorders such as acute myocardial infarction, embolism and stroke are primarily attributed to excessive fibrin accumulation in the blood vessels, usually consequential in thrombosis. Numerous methodologies including the use of anti-coagulants, anti-platelet drugs, surgical operations and fibrinolytic enzymes are employed for the dissolution of fibrin clots and hence ameliorate thrombosis. Microbial fibrinolytic enzymes have attracted much more attention in the management of cardiovascular disorders than typical anti-thrombotic strategies because of the undesirable after-effects and high expense of the latter. Fibrinolytic enzymes such as plasminogen activators and plasmin-like proteins hydrolyse thrombi with high efficacy with no significant after-effects and can be cost effectively produced on a large scale with a short generation time. However, the hunt for novel fibrinolytic enzymes necessitates complex purification stages, physiochemical and structural-functional attributes, which provide an insight into their mechanism of action. Besides, strain improvement and molecular technologies such as cloning, overexpression and the construction of genetically modified strains for the enhanced production of fibrinolytic enzymes significantly improve their thrombolytic potential. In addition, the unconventional applicability of some fibrinolytic enzymes paves their way for protein hydrolysis in addition to fibrin/thrombi, blood pressure regulation, anti-microbials, detergent additives for blood stain removal, preventing dental caries, anti-inflammatory and mucolytic expectorant agents. Therefore, this review article encompasses the production, biochemical/structure-function properties, thrombolytic potential and other surplus applications of microbial fibrinolytic enzymes.
\end{abstract}

Keywords: microbial fibrinolytic enzymes; enzyme production; enzyme purification; characterisation; structural-functional attributes; thrombolytic potential; biopharmaceutical applications

\section{Introduction}

Cardiovascular diseases (CVDs) for patients with myocardial infarct, hypertension, hyperlipidaemia, diabetes mellitus, stenocardia or coronary heart disease are dominant causes in the ensuing upsurge of mortality worldwide [1-3]. The World Health Organization (WHO) demarcated 17.9 million deaths each year from CVDs, an estimated 31\% of deaths globally [4]. Fibrin clots in vivo are formed through activated thrombin (EC 3.4.21.5) and hydrolysed by plasmin (EC 3.4.21.7) as a haemostatic response under standard physiological circumstances to prevent thrombus formation. However, excessive coagulation or irregular fibrin accretion in the blood vessels results in life threatening intravascular clotting, commonly referred to as cardiovascular thrombosis [5]. Anti-thrombotic strategies such as anti-platelet drugs (aspirin and dipyridamole), anti-coagulants (heparin and warfarin) and surgical operations are the keystone of thwarting thrombosis but substantially upsurge the risk of after-effects, specifically haemorrhage [6]. 
It has been shown that microorganisms can secrete enzymes that demonstrate fibrinolytic activity like plasmin, which makes them more accessible and cheaper producers of such enzymes as compared to their analogues. Advances in studies of these kinds of enzymes open up great opportunities in solving the problem of lysis of preformed blood clots. Therefore, an important stage in such studies is the directed search for new producers that have certain advantages over those already known $[7,8]$.

With the emergence of "Biocatalysis" as an eco-technology, a promising perspective of microbial fibrinolytic enzymes has progressively attracted therapeutic prominence because of their comprehensive biochemical diversity, low expense, scale-up feasibility and easy genetic modification which could directly lyse existing thrombus inside the blood vessel $[9,10]$. Scientific reports suggest numerous microbial sources of fibrinolytic enzymes such as bacteria (including actinomycetes), filamentous fungi and microalgae [10,11]. A cultivation-dependent methodology is largely employed for screening microbial producers of fibrinolytic enzymes. However, with an aim of enhanced production/high efficacy: recombinants, mutagens and metagenomic libraries are also created as cultivable microbes and are no more than $1 \%$ of the entire microbial community [10]. Furthermore, different traditional fermented foods are also testified for producing efficient fibrinolytic enzymes, for example: nattokinase extracted from Japanese natto [12,13] and fibrinolytic enzyme [14] from soyabean fermented Douchi efficiently lysed thrombi in vitro and in vivo.

Conventional and statistical optimisation of nutritional components and physicochemical parameters - carbon, nitrogen, substrates, minerals, temperature, $\mathrm{pH}$, rate of agitation and inoculum size-are some of the pivotal approaches stated for the fibrinolytic enzyme's significant fermentative production [15]. Subsequently, with the detection of $\mathrm{pH} /$ temperature/organic solvent stable proteolytic fibrinolytic enzymes, the additional unconventional pharmacological and industrial applicability of such enzymes has also emerged. Some of the recent applications suggest their use as functional drugs/food additives to prevent and cure CVDs, anti-microbials, potential detergent additives for blood stain removal and blood pressure regulators along with mucolytic expectorant agents [12]. Thus, microbial fibrinolytic enzymes have not only emerged as potential biocatalysts with tremendous usage possibilities as prodigious fibrinolytic agents, but they exhibit other miscellaneous applications as well.

Fibrinolytic enzymes (EC 3.4.) of exogenic origin, based on their in vivo working mechanisms are currently distinguished into two categories: plasminogen activators (PAs) and plasmin-like enzymes [16] (Figure 1). The first, being the PAs such as urokinase-type PA (EC 3.4.21.31) and streptokinase (EC 3.4.99.22), convert the inactive precursor of plasmin that is plasminogen into active plasmin and eventually leads to fibrin hydrolyses [17]. The second type of fibrinolytic enzymes are plasmin-like proteins such as nattokinase (EC 3.4.21.62) which directly initiates fibrin hydrolyses and reinstates standard vascular architecture by degrading blood thrombi promptly and completely [17]. Based on the catalytic mechanism, the fibrinolytic enzymes are further categorised as serine protease (for example, Bafibrinase, Terrilitin, Aspergillus ochraceus AO-1 protease) [18-20], metalloprotease (for example, Serratia sp. KG-2-1 metalloprotease) [21] and a mixture of serine metalloprotease (for example, Streptomyces protease, Serratia marcescens subsp. sakuensis) [22,23]. Additionally, intermolecular protein-ligand interactions with an active physiological substrate and activator/inhibitor specification control an enzyme's cellular/biochemical processes. The structural-functional elucidation of enzymes is henceforth essential to study their mechanism of action and ultimately commercialisation [24].

Regardless of their enormous uses, fibrinolytic enzymes exhibit several inadequacies such as low fibrin specificity, short half-life span, allergic reactions, resistance to repercussion and higher therapeutic dosage with increased risk of bleeding complications [5,17]. This, nonetheless, has not stopped the investigation of novel, potent and safe fibrinolytic enzymes. In this review, we will shed light on recent technological advances that facilitate the production of microbial fibrinolytic enzymes along with their properties, thrombolytic potential and additional unconventional applications. 


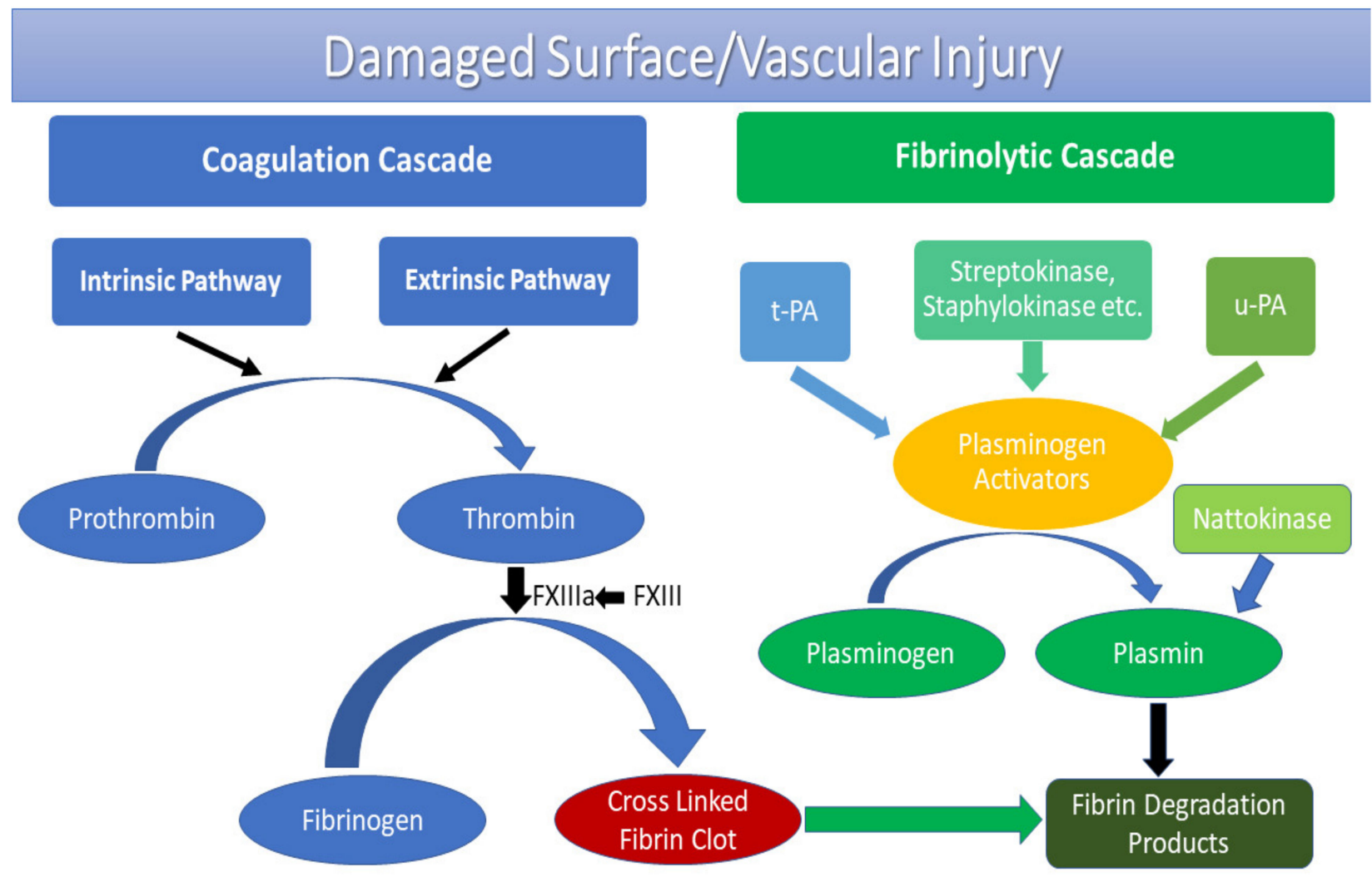

Figure 1. In vivo working mechanism of microbial fibrinolytic enzymes.

\section{Microbial Fibrinolytic Enzymes: Production Status and Diversity}

Microorganisms exhibit a significant role in the mass-production of highly specific, low-cost fibrinolytic enzymes with feasibility of genetic modification through biotechnological approaches. During the past decades, numerous such fibrinolytic enzymes have been tested, specifically from genera Bacillus $[2,5,14,15,18,25-29]$ and Aspergillus $[8,19,20,30-34]$. In addition, fibrinolytic enzymes with varied biochemical characteristics were obtained from bacterial species such as Streptococcus hemolyticus (Streptokinase, exudates of infected wounds) [35], Bacillus subtilis (Nattokinase, Fermented soybeans) [12], Staphylococcus aureus (Staphylokinase, human skin) [36], Bacillus sp. DJ-4 (Subtilisin DJ4, Doen-jang, Korea) [37], fungal species such as Cordyceps militaris [38] and Armillaria mellea [39]. Streptokinase is clinically used as an intravenous thrombolytic agent for preventing CVDs and mentioned in the World Health Organization model lists of essential medicines. It works as a plasminogen activator which forms a 1:1 stochiometric complex with plasmin, resulting in blood clot hydrolysis [40]. The fibrinolytic nattokinase initiates direct fibrin hydrolysis by converting pro-urokinase to urokinase, degrading plasminogen activator inhibitor- 1 and increasing the activity of the tissue plasminogen activator. It has minimal to no after-effects when administered orally in animal/human trials and the National Science Foundation (United States) has specified its safety [12]. The fibrin-specificity of staphylokinase (SAK) is due to the rapid inhibition of the formed plasmin-SAK complex by $\alpha_{2}$-antiplasmin in mammalian plasma and thus allows plasminogen activation at the surface of the fibrin clot [41]. Different sources such as fermented Chungkook-jang (Bacillus sp. CK 11-4) [42], Dosa (Bacillus amyloliquefaciens MCC2606) [43], Douche (B. amyloliquefaciens DC-4) [44], Doen-jang (Bacillus sp. DJ-2, Bacillus sp. DJ-4) [45,46], Jeot-gals (Bacillus sp. KA38) [47], Gembus (Bacillus pumilus 2.g), [48], Kishk (Bacillus megaterium KSK-07) [27] and Moromi (Bacillus subtilis K2) [49], etc., have also been reported to yield enzymes with significant fibrinolytic potential. Probiotic lactic acid bacteria have also shown high proteolytic activity in fermented foods [50,51]. 
Producers of perspective fibrinolytic proteases were found among filamentous fungi (micromycetes). Some of the preparations of micromycete' proteinases have successfully passed preclinical and clinical trials [52,53]. Effective fibrin lysis was found in proteinases from Fusarium oxyporum [54], F. pallidoroseum [55], Paecilomyces tenuipes [56], Mucor subtilissimus [57], Rhizopus chinensis [58] and Rhizomucor miehei [59]. Proteases with plasminogen activating activity were found in representatives of micromycetes of different systematic and ecological-trophic groups: Arthrobotrys longa [60], Tolypocladium inflatum [61], Rhizopus microsporus var. tuberosus [62], Neurospora sitophila [63] and Sarocladium strictum [64].

In addition, research suggests several other proteolytic enzymes with fibrinolytic potential from different bacterial and fungal species which are listed in Table 1.

Table 1. Microbial sources of fibrinolytic enzymes.

\begin{tabular}{|c|c|c|c|}
\hline Collection Site/Source & Microbial Strain & Fibrinolytic Enzyme & Reference \\
\hline Indonesian fermented soybean & $\begin{array}{l}\text { B. cereus } \mathrm{K} 1 \text {, B. subtilis } \mathrm{K} 2 \text {, and B. cereus } \\
\mathrm{K} 3\end{array}$ & - & [65] \\
\hline Marine isolate & B. subtilis D21 & - & [66] \\
\hline $\begin{array}{l}\text { Fermentation with combinations of } \\
\text { microbial strains }\end{array}$ & $\begin{array}{l}\text { B. subtilis GUTU09, Lactobacillus sp., } \\
\text { Bifidobacterium sp. and Mucor sp. }\end{array}$ & Nattokinase & [67] \\
\hline UV mutagenesis of $B$. subtilis HQS-3 & B. subtilis strain WR350 & - & [68] \\
\hline Fermented soybean and soil & B. subtilis & Nattokinase & [69] \\
\hline Garbage dump soil & Serratia sp. KG-2-1 & - & [21] \\
\hline Soil samples & B. cereus RSA1 & - & [5] \\
\hline $\begin{array}{l}\text { Fermented food of North- East } \\
\text { India }\end{array}$ & B. cereus & Bacifrinase & [28] \\
\hline Marine soil & $\begin{array}{c}\text { Streptomyces rubiginosus } \\
\text { VITPSS1 }\end{array}$ & - & {$[70]$} \\
\hline Marine sponges (Agelas conifera) & Streptomyces radiopugnans VITSD8 & - & [71] \\
\hline Fermented food Jotgal (pickled fish) & - & - & [72] \\
\hline $\begin{array}{l}\text { Gut of a Colombian silkworm } \\
\text { hybrid }\end{array}$ & Serratia marcescens C8 & Serratiopeptidase & [73] \\
\hline Marine water & Streptomyces venezuelae & Thrombinase & [74] \\
\hline $\begin{array}{l}\text { Indonesian soybean-based } \\
\text { fermented food }\end{array}$ & Stenotrophomonas sp. & - & {$[75]$} \\
\hline Bovine milk & Streptococcus agalactiae EBL-31 & Streptokinase & [76] \\
\hline $\begin{array}{l}\text { Vietnamese soybean-fermented } \\
\text { food samples }\end{array}$ & B. amyloliquefaciens & - & {$[77]$} \\
\hline Fermented soyabean & B. subtilis QK02 & QK01 and QK02 & {$[78]$} \\
\hline Doen-jang & Bacillus sp. DJ-2 & Bacillopeptidase DJ-2 & {$[45]$} \\
\hline- & Bacillus cereus B80 & - & [79] \\
\hline $\begin{array}{l}\text { China General Microbiological } \\
\text { Culture Collection Center (2577) }\end{array}$ & Cordyceps militaris & $\mathrm{CmFE}$ & [80] \\
\hline Catharanthus roseus (Stem) & Xylaria curta & Xylarinase & [81] \\
\hline $\begin{array}{l}\text { Korean Mushroom Company } \\
\text { (Suwon) }\end{array}$ & Hericium erinaceum & Herinase & [82] \\
\hline Edible mushroom & Pleurotus ferulae & - & [83] \\
\hline $\begin{array}{c}\text { Las Yungas rainforest (Tucumán, } \\
\text { Argentina) }\end{array}$ & Bionectria sp. & - & {$[84]$} \\
\hline
\end{tabular}


Table 1. Cont.

\begin{tabular}{|c|c|c|c|}
\hline Collection Site/Source & Microbial Strain & Fibrinolytic Enzyme & Reference \\
\hline $\begin{array}{l}\text { Korean agricultural culture } \\
\text { collection }\end{array}$ & Schizophyllum commune & Mushrokinase & [85] \\
\hline- & Aspergillus ochraceus 513 & - & {$[86]$} \\
\hline Commercial rice-koji & Aspergillus oryzae KSK-3 & - & [87] \\
\hline Starter for brewing rice wine & Rhizopus chinensis $12 \#$ & - & [88] \\
\hline Caatinga soil (Brazil) & Mucor subtilissimus & - & [89] \\
\hline Herbal medicine & Cordyceps sinensis & CSP & [90] \\
\hline $\begin{array}{l}\text { Korean agricultural culture } \\
\text { collection }\end{array}$ & Fomitella fraxinea & FFP1 and FFP2 & [91] \\
\hline Marine isolate & Codium divaricatum & CDP & [92] \\
\hline Marine isolate & Codium latum & CLP & [93] \\
\hline Marine isolate & Codium intricatum & CIP-I and CIP-II & [94] \\
\hline $\begin{array}{l}\text { Shiokara (Japanese traditional } \\
\text { fermented food) }\end{array}$ & - & Katsuwokinase & [95] \\
\hline Mutant of Streptomyces spheroides 35 & Streptomyces spheroides M8-2 & - & [96] \\
\hline $\begin{array}{l}\text { Centre of Cultures of the National } \\
\text { Research Centre (Cairo, Egypt) }\end{array}$ & Cochliobolus lunatus & - & [97] \\
\hline- & Actinomyces thermovulgaris & - & [98] \\
\hline Soil isolate, nematophagus & Arthrobotrys longa Mecht.1 & Longolytin & [60] \\
\hline $\begin{array}{l}\text { Microorganisms Collection of } \\
\text { Department of Microbiology, } \\
\text { Moscow State University }\end{array}$ & Aspergillus flavus O-1 & - & [32] \\
\hline $\begin{array}{l}\text { Microorganisms Collection of } \\
\text { Department of Microbiology, } \\
\text { Moscow State University }\end{array}$ & A. fumigatus D-1 & - & [99] \\
\hline $\begin{array}{c}\text { Regional Hospital and University of } \\
\text { Angers }\end{array}$ & A. fumigatus CBS 113.26 & - & [100] \\
\hline Soil isolate & A. brasiliensis AUMC 9735 & - & [8] \\
\hline Soil isolate & A. brasiliensis BCW2 & & [101] \\
\hline Soil near slaughterhouse & A. carbonarius S-CSR-0007 & - & {$[31]$} \\
\hline $\begin{array}{l}\text { All-Russian collection of } \\
\text { microorganisms, Moscow }\end{array}$ & A. ochraceus VKM F-4104D & $\mathrm{AO}-3$ & [20] \\
\hline Soil isolate & A. tamarii SAS 02 & - & [33] \\
\hline Soil isolate & A. terricola & Terrilytin & [19] \\
\hline $\begin{array}{l}\text { Microorganisms Collection of } \\
\text { Department of Microbiology, } \\
\text { Moscow State University }\end{array}$ & A. ustus 1 & - & [30] \\
\hline $\begin{array}{l}\text { Tectona grandis (Teak wood) } \\
\text { infected leaf sample }\end{array}$ & Cladosporium sp. & - & [102] \\
\hline Sodx Co., Osaka, Japan & Fusarium sp. BLB & FP & [103] \\
\hline Chrysanthemum stems & Fusarium sp. CPCC 480097 & $\mathrm{Fu}-\mathrm{P}$ & [104] \\
\hline Soil isolate & Fusarium sp. CSN-6 & - & [105] \\
\hline Soil isolate & Mucor subtillissimus UCP 1262 & - & [106] \\
\hline $\begin{array}{l}\text { Starter used for fermenting soybean } \\
\text { paste }\end{array}$ & Neurospora sitophila & - & [63] \\
\hline
\end{tabular}


Table 1. Cont.

\begin{tabular}{cccc}
\hline Collection Site/Source & Microbial Strain & Fibrinolytic Enzyme & Reference \\
\hline $\begin{array}{c}\text { Compost preparations of factory of } \\
\text { organic fertilizers, Egypt }\end{array}$ & Oidiodendrum flavum & - & [107] \\
\hline Hibiscus leaves & Penicillium citrinum & & [108] \\
\hline $\begin{array}{c}\text { Contaminated soil of poultry } \\
\text { slaughterhouse }\end{array}$ & Penicillium sp. BF20 & - & [109] \\
\hline $\begin{array}{c}\text { Daqu (a fermentative } \\
\text { agent used in the production of } \\
\text { Chinese liquor and vinegar) }\end{array}$ & Rhizopus microsporus var. tuberosus & Proteinase III & [62] \\
\hline Mycophylic strain & Sarocladium strictum & - & [64] \\
\hline Human sputum & Scedosporium apiospermum & [110] \\
\hline Insects' remains & Tolypocladium inflatum $\mathrm{k} 1$ & {$[61]$} \\
\hline
\end{tabular}

\section{Molecular Cloning, Overexpression and Construction of Genetically Modified Strains for Production of Fibrinolytic Enzymes}

Though fibrinolytic enzymes possess significant thrombolytic potential, large production with high specificity and stability of protein is required for clinical practices, which can be achieved by techniques such as the construction of genetically modified strains, molecular cloning and overexpression, etc. In biotechnological applications, the non-pathogenicity of $B$. subtilis and its ability of exuding valuable extracellular proteins in growth medium signify its suitability as an efficient host for the expression of foreign proteins [111]. Gene encoding bacillopeptidase F was cloned from B. subtilis LZW, expressed in B. subtilis WB700 and the catalytic mechanism of proteins along with the activity of $C$-terminal truncation variants in sustaining enzymatic activity were interpreted [112]. A significant increase in fibrinolytic activity (80-200 urokinase $\mathrm{U} / \mathrm{mL}$ ) was observed when the gene expression of subtilisin DFE in B. subtilis was mediated by a promoter of $\alpha$-amylase gene from $B$. amyloliquefaciens DC-4 [113]. Subtilisin DFE was actively expressed by vector pSUGV4 in protease-deficient $B$. subtilis WB600 in another study performed by Peng et al. [114]. Additionally, fibrinolytic gene aprE2 was overexpressed in protease-deficient heterologous B. subtilis [115]. One of the highest protein yields ( $600 \mathrm{mg} / \mathrm{L}$ of growth medium) was attained when the nattokinase gene from the B. subtilis strain VTCC-DVN-12-01 was expressed in eight-protease-gene-deficient $B$. subtilis WB800 under the control of promoter acoA [116]. Liu and Song also successfully achieved the cloning and functional expression of nattokinase in B. subtilis [117].

Some research studies report the formation of insoluble aggregates without the specific activity of enzymes when expressed in E. coli (Nattokinase and Subtilisin DFE) [118]. However, the successful expression of fibrinolytic enzymes in E. coli is also stated in literature. A 2.2-fold higher specific activity was observed when a fibrinolytic enzyme encoding Gene aprE176 was successfully cloned from B. subtilis HK176 and overexpressed in E. coli BL21(DE3) [119]. High subtilisin activity by transformant was reported when the subtilisin gene from B. amyloliquefaciens DC-4 and B. subtilis PTCC 1023 was expressed in E. coli BL21 (DE3) [120-122]. B. pumilus BS15 obtained fibrinolytic gene aprEBS15 was cloned in pHY300PLK (Bacillus-E. coli shuttle vector) and overexpressed in E. coli BL21 (DE3). Similar results with higher fibrinolytic activity were observed by $B$. subtilis transformant harboring pHYBS15 in the same study [123]. Another novel fibrinolytic enzyme (BsfA) from B. subtilis ZA400 was cloned and expressed in E. coli [124].

Information on the cloning of micromycetes-producers of fibrinolytic enzymes is scarce and scattered, which is explained by the simplicity of the cultivation of "wild" strains, because the genes of proteolytic enzymes of filamentous fungi, like all eukaryotes, contain intron regions. 
However, the case of fungus Cordyceps militaris fibrinolytic enzyme (CmFE) has shown that there was one open reading frame of 759 bp encoding a "pre-pro-protein" of 252 amino acids. The protease was successfully cloned and recombinant CmFE was expressed as $28 \mathrm{kDa}$ extracellular enzyme in yeast Pichia pastoris vector (pPIC9K under the AOX1 promoter) [80].

Techniques such as mutagenesis and random screening of mutants have also been employed for the improvement of microbial strains, especially bacterial. Fibrinolytic activity was doubled in research conducted by Lai et al. through in vitro random mutagenesis by ethyl methane sulfonate [125]. In another study, ultraviolet radiation mutated strain Bacillus sp. SFN01 displayed higher clot lysis activity (1 unit of enzyme resulted in the complete dissolution of the blood clot) than the wild strain [126]. In a similar study by Raju et al. physical/chemical mutagenesis such as ultraviolet radiation, ethyl methane sulfonate and ethidium bromide treated Bacillus cereus GD 55 showed optimal production of the fibrinolytic enzyme [127]. Mutations were induced in strain Streptomyces venezuelae by ultraviolet rays and ethyl methane sulfonate for the enhanced production of thrombinasefibrinolytic enzymes [74]. A combination of process optimisation, codon optimisation and gene dosage has been successfully employed for high production of fibrinolytic enzymefibase from marine Bacillus subtilis, which was expressed in Komagataella phaffii GS115 [66]. Another approach of directed evolution (DNA family shuffling) was used to improve the fibrinolytic activity of nattokinase from Bacillus natto. A mutant library was generated by shuffling three homologous genes from B. licheniformis CICC 10092, B. amyloliquefaciens CICC 20164 and B. natto AS 1.107. One desired mutant with approximately 2.3 times higher catalytic efficiency than that of the wild strain was obtained after three rounds of DNA shuffling. The molecular modelling analysis proposed that mutations alter the surface conformation of the substrate-binding pocket and ultimately affect the enzymatic function [128]. Thus, the listed biotechnological approaches were proved efficient enough for the optimal production of fibrinolytic enzymes with enhanced specific activity.

\section{Process Optimisation Techniques}

Culture media optimisation along with the combination of biotechnological techniques play a significant role in maximising the production yield of fibrinolytic enzymes. Research suggests both traditional media optimisation one-variable-at-a-time, and statistical optimisation approaches for the production of fibrinolytic enzymes. The one-factor-at-a-time strategy was used to optimise the fermentation conditions for production of the fibrinolytic enzyme from Citrobacter braakii, wherein a 5.5-fold increase in enzyme production $(198.6 \mathrm{FU} / \mathrm{mL})$ was observed from the initial medium $(36.15 \mathrm{FU} / \mathrm{mL})$ [129]. However, optimisation of media components by traditional method is enormously time consuming and costly [5]. To overcome this complexity, a statistically optimised medium is employed for designing experiments, building models and analysis of the interaction of factors for desirable responses using the minimum number of experiments in most of the research. Statistical approaches such as fractional factorial design (FFD), response surface methodology (RSM), Plackett-Burman factorial design (PB Design), central composite design (CCD), central composite rotatable design (CCRD), Box-Behnken design, Taguchi orthogonal array design, etc., are employed. Vijayaraghavan et al. achieved the optimisation of process parameters (nutrient and physical parameters such as carbon sources, nitrogen sources, salt solutions, incubation temperature, $\mathrm{pH}$, inoculum, etc.) for fibrinolytic enzyme production initially by one variable approach and further optimised significant variables by the statistical two-level full factorial design method [130]. A similar approach was opted by Wu et al. in 2019, in which both single-factor optimisation followed by $L_{9}\left(3^{4}\right)$ orthogonal design, an orthogonal array of four factors with three levels, were employed to optimise the process parameters [68]. A two-fold increase in the production of fibrinolytic enzymes from Bacillus cereus RSA1 was observed when media was optimised using the Plackett-Burman design, response surface methodology and central composite design [5]. Such optimisation methodologies thus aid in evaluating optimum nutrient composition, comprehending the 
interaction between different parameters and conferring reliability, henceforth saving time and energy. A detailed list of diverse media optimisation techniques used is presented in Table 2.

Table 2. Process optimisation techniques for optimal production of fibrinolytic enzymes.

\begin{tabular}{|c|c|c|c|}
\hline Microbial Strain & Optimisation Technique & Fibrinolytic Activity (U/mL) & Reference \\
\hline Fictibacillus sp. SKA27 & CCD and artificial neural network (ANN) & 4175.41 & [131] \\
\hline Bacillus subtilis & CCD & 18.9 & [132] \\
\hline Bacillus cereus RSA1 & PB Design, RSM and CCD & 30.75 & [5] \\
\hline Serratia rubidaea KUAS001 & One factor at a time approach & 394.9 & [133] \\
\hline Bacillus subtilis & PB Design and Box-Behnken design & 77,400 & [134] \\
\hline Streptomyces radiopugnans_VITSD8 & $\begin{array}{l}\text { One factor at a time and Fractional } \\
\text { factorial design }\end{array}$ & $663.5 \pm 1.43$ & [135] \\
\hline Bacillus natto & $\begin{array}{l}2^{5-1} \text { fractional factorial design, } \\
\text { Box-Behnken design and RSM }\end{array}$ & 20.83 & [136] \\
\hline Bacillus subtilis & Taguchi experimental design & 130.96 & [137] \\
\hline Bacillus subtilis ICTF-1 & $\mathrm{L}(18)$-orthogonal array method & 8814 & [138] \\
\hline Bacillus sphaericus MTCC 3672 & $2^{k}$ fractional factorial CCRD, RSM & 384 & [139] \\
\hline Shewanella sp. IND20 & $\begin{array}{c}\text { One-factor-at-a-time, e } 2^{5} \text { factorial design, } \\
\text { RSM, CCD }\end{array}$ & 2751 & [140] \\
\hline Xylaria curta & One-variable-at-a-time approach & 9.22 & [81] \\
\hline Pseudoalteromonas sp. IND11 & Two-level full factorial design, RSM, CCD & 1573 & [141] \\
\hline
\end{tabular}

In the cases of obtaining fibrinolytic enzymes of fungal origin, the most preferred strategy is the transition to the solid-state fermentation cultivation of producers. Solidstate fermentation is a method of growing filamentous fungi on the surface of solid moist particles of natural origin or inert synthetic ones. At the same time, the yield of enzymes in such a cultivation system increases significantly by 1.5 times and more [142]. For example, when cultivating Fusarium pallidoroseum on wheat bran, it was possible to obtain an increase in the secretion of fibrinolytic protease by 1.58 times [55], and when cultivating Aspergillus ochraceus on silica gel and vermiculite specific activity was 1.5-3.5 times higher than in a submerged culture $[143,144]$. The high impact in such types of cultivation on fibrinolytic activity optimisation effect different parameters such as time, inoculum ratio, moisture content and particle size. For Penicillium chrysogenum SGAD12 grown on rice chaff the fibrinolytic activity was maximized at $104 \mathrm{~h}, 7 \%(v / v)$ inoculum ratio, $35-45 \%(v / w)$ moisture content and $500 \mu \mathrm{m}$ particle size [145].

Another way to increase the secretion of fibrinolytic enzymes can be considered immobilisation. Studies carried out with microscopic fungi have shown the promise of this method, for example, culture Penicillium chrysogenum $\mathrm{H} 9$ demonstrated stable and high enzyme production in Ca-alginate beads in comparison to free cells [146]. The immobilised cells of Aspergillus ochraceus VKM-F4104D mycelium demonstrated increased stability and were able to synthesise fibrinolytic protease at the maximum level for 10 or more days. In addition, it was shown that immobilised mycelial cells of the producer during cultivation can be used repeatedly (up to five cycles) [147].

\section{Recovery and Purification of Fibrinolytic Enzymes}

In vitro obtained crude fibrinolytic enzymes might be employed for commercial applicability. However, the fermented culture of microbial biomass when harvested is exposed to extreme variation in environmental conditions which leads to contaminated recovery and fails to maintain the activity/stability of enzymes. Therefore, purification of enzymes is objectified to render them contaminant-free and upsurge their shelf life/stability [148]. 
Furthermore, biochemical properties (kinetics of clot dissolution, thermodynamic studies, etc.) and a better understanding of the structural-functional aspects of fibrinolytic enzymes can only be achieved in its pure form $[5,28]$. Additionally, formulations for commercial and therapeutic applications are designed only from purified enzymes [149]. Continuous disc centrifuges and vacuum drum filters are generally used for the exclusion of contaminants such as microbial cells, colloids and solids from the fermentation broth [5,150-153]. Chemical treatment of the fermentation broth and the addition of flocculating/coagulating agents is implemented to remove colloidal solids, prevent any significant loss in enzymatic activity and clogging of filters [154]. Extracting agent: Isooctane $(50 \mathrm{mM})$ for fibrinolytic enzyme $(1 \mathrm{mg} / \mathrm{mL})$ in $20 \mathrm{mM} / \mathrm{L}$ at $240 \mathrm{rpm}, 20^{\circ} \mathrm{C}$ and $\mathrm{pH} 4-7$ significantly aided in maximum specific activity [155]. Microbial cell-free extract is also concentrated to obtain proteins in precipitated form by techniques such as ethanol precipitation, ammonium sulphate precipitation, acetone precipitation, dialysis, ultracentrifugation and ultrafiltration $[5,9,156-161]$. Such methodologies are used either individually or in combinations, accompanied by chromatographic techniques for further purification. Chromatofocusing, fast protein liquid chromatography, high performance liquid chromatography, affinity column chromatography, gel filtration chromatography, ion exchange chromatography and hydrophobic interaction chromatography are commonly employed techniques for fibrinolytic enzyme purification [2,5,100-108,110,162-168]. Some recent purification studies of microbial fibrinolytic enzymes employed by researchers are discussed below. A novel fibrinolytic enzyme from Streptomyces radiopugnans VITSD8 was purified using solid ammonium sulphate $(0-85 \%)$ precipitation accompanied by dialysis against Tris- $\mathrm{HCl}$ buffer $(10 \mathrm{mM}, \mathrm{pH} 7.2)$ and concentrated with Millex syringe filter-ultrafiltration membrane. The enzyme was further purified using gel filtration (Sepharose CL-6B column, $120 \mathrm{~cm} \times 2.2 \mathrm{~cm}$ ) and a Poros-HQ ion exchange column $(10 \mathrm{~cm} \times 1 \mathrm{~cm})$. A 22.36-fold increase in specific activity $(3891 \mathrm{U} / \mathrm{mg})$ of the purified enzyme was observed with a yield of $35 \%$ relative to crude enzymes [71]. A successful combination of purification techniques was reported by Hu et al. for purification of a highly potent and novel fibrinolytic enzyme DFE27 from Bacillus subtilis DC27 screened from Douchi. The enzyme was purified by ammonium sulphate (40-70\%) precipitation, overnight dialysis (20 mM Tris-HCl buffer, $\mathrm{pH}$ 8.8), UNOsphere $\mathrm{Q}$ column chromatography, gel filtration (Sephadex G-75) and high-performance liquid chromatography. DFE27 was 69.1-fold purified (11274.4 IU/mg) with a recovery rate of $12.73 \%$ [2]. Bacifrinase from Bacillus cereus was well purified with ice-cold acetone $(70 \%)$ precipitation and fast protein liquid chromatography (HiLoad Superdex 75 pg 16/60). An 18.3-fold purification with specific activity of $52.4 \mathrm{U} / \mathrm{mg}$ was observed [28]. Maximum 21.2-fold purification with specific activity of $2607.8 \mathrm{U} / \mathrm{mL}$ was obtained on the subsequent purification of fibrinolytic protease from Bacillus cereus with an anion exchange column (DEAE-sepharose) [169].

Another method for in-laboratory purification of fibrinolytic enzymes is isoelectrofocusing. The method was used for obtaining pure enzymes for their characterisation and further special studies $[20,30,32,64,99]$. Isoelectrofocusing allows one not only to isolate enzymes, but also to get a primary idea of their properties and compare fibrinolytic enzymes from different producers. Thus, a comparison of Aspergillus ochraceus L-1 and Aspergillus terreus 2 proteases showed that cultures are promising highly active producers of proteases of different activities toward human hemostasis proteins, activation of proenzymes such protein $\mathrm{C}$, factor $\mathrm{X}$ and displayed plasmin, and thrombin-like activities. Using isoelectrofocusing demonstrated that both enzymes differ in the isoelectric points (nearly by one unit) and by the mechanism of action [170].

However, some studies report several disadvantages associated with these complex downstream purification technologies, such as unsustainability, being time-intensive, depletion of native protein structure, declined enzyme activity and production quality. Therefore, in such cases, techniques, namely AOT (sodium di [2-ethylhexyl] sulfosuccinate)/isooctane reverse micelles system, aqueous two-phase systems (poly-ethylene glycol $4000 / 8000$ and sodium sulfate) and three-phase partitioning (protein precipitation by mixture of t-butanol and ammonium sulfate) are used. Liu et al. purified nattokinase by AOT 
(sodium di [2-ethylhexyl] sulfosuccinate)/isooctane reverse micelles system with up to $80 \%$ activity recovery and a purification factor of 3.9 [171]. Fibrinolytic enzymes from $B$. subtilis DC-2 and M. subtilissimus UCP 1262 were well purified by aqueous two-phase systems (polyethylene glycol/sodium sulfate) [172,173]. Henceforth, numerous purification methodologies opted for in research studies on fibrinolytic enzymes have significantly enhanced their specific activity with a high recovery rate and can be further formulated for commercial/therapeutic practices.

\section{Physicochemical Characterisation of Microbial Fibrinolytic Enzymes}

Physiochemical properties such as optimal $\mathrm{pH} /$ temperature, molecular mass, effect of metal ions/inhibitors and substrate specificity of fibrinolytic enzymes have been extensively studied. Table 3 summarises important characteristics of microbial fibrinolytic enzymes. Most of the reported fibrinolytic enzymes are active at neutral to alkaline $\mathrm{pH}$ with optimal activity amid pH 7 to 10 [2,5,8,19,62-64,104,174-176], while some fibrinolytic enzymes possess optimal specific activity at extreme acidic or basic conditions. Fibrinolytic enzymes from Flammulina velutipes and Pseudomonas baetica SUHU25 were found to exhibit optimal activity at pH $6[158,177]$. Nattokinase extracted from mutant Pseudomonas aeruginosa CMSS obtained its highest activity at pH 5 [159]. Fibrinolytic enzymes from fermented shrimp paste and Staphylococcus sp. strain AJ from Korean salt-fermented Anchovy-jeot exhibited optimal activity from pH 3.0-7.0 and pH 2.5-3.0, respectively [178,179]. Optimum $\mathrm{pH}$ for the activity of fibrinolytic enzymes CFR15 and CK from B. amyloliquefaciens MCC2606 and Bacillus sp. strain CK 11-4, respectively, was found to be pH 10.5 [42,43]. Fungal enzymes, such as Aspergillus ustus 1, Arthrobotrys longa 1 and some others are able to hydrolyse fibrin at $\mathrm{pH} 6.0[30,176]$. Optimal temperature widely ranged from $20-70{ }^{\circ} \mathrm{C}[20,31,42,100,101,177,180]$, mostly approx. $50{ }^{\circ} \mathrm{C}$ for bacterial proteases $[5,181]$ and $37-45^{\circ} \mathrm{C}$ for some fungal species $[20,30,62,101,104,107]$. The molecular weight of fibrinolytic enzymes of different origins broadly varied from $14 \mathrm{kDa}$ to $97 \mathrm{kDa}[56,140,172]$, mostly within $27 \mathrm{kDa}$ and $44 \mathrm{kDa}[5,9,182,183]$.

The effect of metal ions/inhibitors on the fibrinolytic activity of enzymes depends on its nature of action, i.e., serine protease, metalloprotease or serine metalloprotease. A wide range of metal ions $\left(\mathrm{Na}^{+}, \mathrm{Ag}^{+}, \mathrm{K}^{+}, \mathrm{Fe}^{2+}, \mathrm{Ti}^{2+}, \mathrm{Mg}^{2+}, \mathrm{Zn}^{2+}, \mathrm{Ni}^{2+}, \mathrm{Co}^{2+}, \mathrm{Ca}^{2+}\right.$, $\left.\mathrm{Mn}^{2+}, \mathrm{Cu}^{2+}, \mathrm{Hg}^{2+}, \mathrm{Al}^{3+}, \mathrm{Fe}^{3+}\right)$ have been studied for their effect on the biological activity of enzymes. The activity of few fibrinolytic proteases was influenced by divalent metal ions like $\mathrm{Mg}^{2+}, \mathrm{Fe}^{2+}, \mathrm{Mn}^{2+}, \mathrm{Mg}^{2+}, \mathrm{Ca}^{2+}$ and inhibited by $\mathrm{Cu}^{2+}, \mathrm{Fe}^{3+}, \mathrm{Zn}^{2+}, \mathrm{Hg}^{2+}$, $\mathrm{Al}^{3+},[56,62,63,163,184]$. Some fibrinolytic metalloproteases require divalent ions $\mathrm{Co}^{2+}, \mathrm{Ni}^{2+}$, $\mathrm{Zn}^{2+}$ for their activity [42,185]. Among inhibitors, Di-isopropyl fluorophosphate (DFP) and phenyl methyl sulfonyl fluoride (PMSF) are the frequently used irreversible serine protease inhibitors $[5,19,20,27,30-32,63,92]$. Inhibitors such as ethylene diamine tetra acetic acid (EDTA), ethyleneglycol bis(2-aminoethyl ether)- $N, N, N^{\prime}, N^{\prime}$-tetraacetic acid (EGTA) and 1, 10 phenanthroline strongly inhibit the fibrinolytic activity of metalloproteases [73,163,183]. In contrast, the fibrinolytic activity of the third 'serine metalloprotease' class of enzymes is inhibited by both serine and metalloprotease inhibitors [22,23,58,104].

The action of purified fibrinolytic enzymes has been studied on various natural protein substrates such as fibrin, fibrinogen, gelatin, casein, bovine serum albumin (BSA), keratin, collagen, globulin, azoalbumin and haemoglobin $[23,30,32,90,99,130]$. The high substrate specificity of fibrinolytic enzymes is testified towards fibrin, which is a more distinctive feature than other reported proteases with broad substrate specificity. Fibrinolytic enzyme CK produced from Bacillus sp. strain CK11-4, screened from Chungkook jang possesses an 8-fold higher specific activity towards fibrin than substilisin Carlsberg, an alkaline protease with a similar $N$-terminal sequence [42]. In another study, the ratio of specific fibrinolytic to caseinolytic activity of subtilisin DJ-4 from Bacillus sp. DJ-4 was 3.97 and 2.67-fold higher than subtilisin Carlsberg and subtilisin BPN, correspondingly [37]. For some filamentous fungi, it was shown that the ratio of overall proteolytic (non-specific) 
activity to fibrinolytic activity is one of the effective fibrin hydrolysis criteria and it is within the values $0.18-0.57$ [186].

Microbial fibrinolytic enzyme specificity has been spectrophotometrically assessed by deploying synthetic substrates D-Val-Leu-Lys-pNA, N-Benzoyl-Pro-Phe-Arg-p-NA, H-DVal-Leu-Lys-pNA (plasmin substrate), MeO-Suc-Arg-Pro-Tyr-pNA, N-succinyl-Ala-AlaPro-Phe-p-NA, (chymotrypsin/subtilisin substrate) and D-Val-leu-Arg-pNA (kallilrein substrate), pyro-Glu-Gly-Arg-pNA (urokinase substrate), H-D-Phe-Pip-Arg-pNA, N-BenzoylPhe-Val-Arg-pNA, Tos-Gly-Pro-Arg-pNA (thrombin/trypsin substrate) [2,27,42,48,177,180]. Fibrinolytic enzymes QK-1 (plasmin-like serine protease) and QK-2 (subtilisin-family serine protease) obtained from Bacillus subtilis QK02 exhibited higher activity towards H-DVal-Leu-Lys- pNA and N-succinyl-Ala-Ala-Pro-Phe-p-NA, respectively [78]. Fibrinolytic enzymes DFE27 (tissue-type plasminogen activator) from B. subtilis DC27 and AO-3 from Aspergillus ochraceus VKM F-4104D showed specificity towards plasmin substrate D-ValLeu-Lys-pNA $[2,20]$. A subtilisin-like fibrinolytic enzyme from Lactobacillus plantarum KSK-II hydrolysed Suc-Ala-Ala-Pro-Phe-pNA [187]. A fibrinolytic protease secreted by micromycete Sarocladium strictum was able to actively split off a chromogenic peptide substrate pGlu-Gly-Arg-pNA [26].

Details of various physiochemical properties of bacterial and fungal fibrinolytic enzymes are mentioned in Table 3.

Table 3. Physiochemical properties of microbial fibrinolytic enzymes.

\begin{tabular}{|c|c|c|c|c|c|}
\hline $\begin{array}{l}\text { Fibrinolytic } \\
\text { Enzyme }\end{array}$ & $\begin{array}{c}\text { Microbe } \\
\text { Associated }\end{array}$ & $\begin{array}{l}\text { Molecular Weight, } \\
\text { Optimal pH and } \\
\text { Temperature }\end{array}$ & Functional Moiety & Mechanism of Action & Reference \\
\hline Streptokinase & $\begin{array}{l}\text { Streptococcus } \\
\text { hemolyticus }\end{array}$ & $\begin{array}{l}47 \mathrm{KDa} \\
\mathrm{pH} 7.5 \\
37{ }^{\circ} \mathrm{C}\end{array}$ & $\begin{array}{l}\text { Single polypeptide chain } \\
\text { ( } 414 \text { amino acids) having } \\
\text { multiple structural } \\
\text { domains }(\alpha, \beta, \curlyvee)\end{array}$ & $\begin{array}{l}\beta \text { domain form SK } \\
\text { plasminogen complex } \\
\text { resulting in activation } \\
\text { of plasminogen }\end{array}$ & [35] \\
\hline Staphylokinase & $\begin{array}{l}\text { Staphylococcus } \\
\text { aureus }\end{array}$ & $\begin{array}{l}15.5 \mathrm{KDa} \\
\mathrm{pH} 8.5 \\
37^{\circ} \mathrm{C}\end{array}$ & $\begin{array}{c}\text { Single polypeptide chain } \\
\text { (136 amino acids) } \\
\text { without disulphide } \\
\text { bridge }\end{array}$ & $\begin{array}{l}\text { Higher affinity with } \\
\text { traces of plasmin } \\
\text { resulting in } \\
\text { plasminogen } \\
\text { activation }\end{array}$ & [36] \\
\hline Serrapeptase & $\begin{array}{l}\text { Serratia marcescens } \\
\quad \text { Strain E } 15\end{array}$ & $\begin{array}{l}45-60 \mathrm{KDa} \\
\mathrm{pH} 9 \\
40{ }^{\circ} \mathrm{C}\end{array}$ & $\begin{array}{l}\text { Metalloprotease } \\
\text { containing } 3 \text { zinc atoms } \\
\text { and one active site }\end{array}$ & $\begin{array}{c}\text { Cleaves peptide bond } \\
\text { linkages }\end{array}$ & [188] \\
\hline $\begin{array}{l}\text { Nattokinase (wild } \\
\text { type) }\end{array}$ & $\begin{array}{c}\text { Bacillus subtilis YF } \\
38, \text { natto }\end{array}$ & $\begin{array}{l}27.7 \mathrm{KDa} \\
\mathrm{pH} 8.6\end{array}$ & $\begin{array}{l}\text { Conserved catalytic } \\
\text { triad }\left(\mathrm{Asp}^{32}, \mathrm{His}^{64} \text { and }\right. \\
\left.\text { Ser }^{221}\right) \text {, oxyanion } \\
\text { hole }\left(\mathrm{Asn}^{155}\right) .\end{array}$ & $\begin{array}{l}\text { Properties resemble } \\
\text { plasmin and enhance } \\
\text { production of plasmin } \\
\text { and clot dissolving } \\
\text { agents }\end{array}$ & [189] \\
\hline Nattokinase & $\begin{array}{c}\text { Pseudomonas } \\
\text { aeruginosa CMSS }\end{array}$ & $\begin{array}{l}21 \mathrm{KDa} \\
7 \mathrm{pH} \\
25^{\circ} \mathrm{C}\end{array}$ & $\begin{array}{l}\text { Similar to wild type } \\
\text { nattokinase with } \\
\text { two-fold increase in } \\
\text { enzymatic activity }\end{array}$ & $\begin{array}{l}\text { Similar to wild type } \\
\text { nattokinase }\end{array}$ & [190] \\
\hline $\begin{array}{l}\text { CK fibrinolytic } \\
\text { enzyme }\end{array}$ & Bacillus sp. CK 11-4 & $\begin{array}{l}28.2 \mathrm{KDa} \\
\mathrm{pH} 10.5 \\
70{ }^{\circ} \mathrm{C}\end{array}$ & $\begin{array}{l}\text { Thermolytic alkaline } \\
\text { serine protease (1882 } \\
\text { protein atoms, } 2 \text { calcium } \\
\text { ions and } 44 \text { water } \\
\text { molecules) }\end{array}$ & $\begin{array}{c}\text { Enhanced production } \\
\text { of tissue plasminogen } \\
\text { activator }\end{array}$ & [42] \\
\hline $\begin{array}{l}\text { Fibrinolytic } \\
\text { enzyme }\end{array}$ & Bacillus sp. KA38 & $\begin{array}{l}41 \mathrm{KDa} \\
\mathrm{pH} 7 \\
40{ }^{\circ} \mathrm{C}\end{array}$ & Metalloprotease & $\begin{array}{l}\text { Degrade fibrin or form } \\
\text { plasmin from } \\
\text { plasminogen }\end{array}$ & [47] \\
\hline
\end{tabular}


Table 3. Cont.

\begin{tabular}{|c|c|c|c|c|c|}
\hline $\begin{array}{l}\text { Fibrinolytic } \\
\text { Enzyme }\end{array}$ & $\begin{array}{l}\text { Microbe } \\
\text { Associated }\end{array}$ & $\begin{array}{l}\text { Molecular Weight, } \\
\text { Optimal pH and } \\
\text { Temperature }\end{array}$ & Functional Moiety & Mechanism of Action & Reference \\
\hline CFR 15 protease & $\begin{array}{c}\text { Bacillus } \\
\text { amyloliquefaciens } \\
\text { MCC2606 } \\
\text { (strain CFR 15) }\end{array}$ & $\begin{array}{l}32 \mathrm{KDa} \\
\mathrm{pH} 10.5 \\
45^{\circ} \mathrm{C}\end{array}$ & $\begin{array}{c}\text { Serine protease (catalytic } \\
\text { triad: } \operatorname{His}^{57}, \operatorname{Ser}^{195}, \\
\operatorname{Asp}^{102} \text { ) }\end{array}$ & $\begin{array}{l}\text { Degrade ( } \alpha \text { polymer, } \beta \\
\text { chain, } \gamma-\gamma \text { dimer, } \alpha \\
\text { chain) of fibrin }\end{array}$ & [43] \\
\hline- & $\begin{array}{l}\text { Bacillus } \\
\text { amyloliquefaciens } \\
\text { An6 }\end{array}$ & $\begin{array}{l}30 \mathrm{KDa} \\
\mathrm{pH} 9 \\
60{ }^{\circ} \mathrm{C}\end{array}$ & Serine protease & $\begin{array}{l}\text { Degrade fibrin or form } \\
\text { plasmin from } \\
\text { plasminogen }\end{array}$ & [191] \\
\hline Subtilisin DJ-4 & Bacillus sp. DJ-4 & $\begin{array}{l}29 \mathrm{KDa} \\
\mathrm{pH} 10 \\
40{ }^{\circ} \mathrm{C}\end{array}$ & $\begin{array}{c}\text { Plasmin-like serine } \\
\text { protease }\end{array}$ & $\begin{array}{l}\text { Rapid hydrolysis of } \\
\alpha-\alpha, \beta-\beta, ' \gamma \text { chains of } \\
\text { fibrin }\end{array}$ & [37] \\
\hline Subtilisin QK02 & Bacillus sp. QK02 & $\begin{array}{l}28 \mathrm{KDa} \\
\mathrm{pH} 8.5 \\
55{ }^{\circ} \mathrm{C}\end{array}$ & $\begin{array}{l}\text { Subtilisin-family serine } \\
\text { protease (Asp 32, His } 64 \\
\text { and Ser 221) }\end{array}$ & $\begin{array}{l}\text { Catalytic triad plays } \\
\text { an important role in } \\
\text { cleaving peptide }\end{array}$ & [78] \\
\hline Subtilisin DFE & $\begin{array}{c}\text { Bacillus } \\
\text { amyloliquefaciens } \\
\text { DC } 4\end{array}$ & $\begin{array}{l}28 \mathrm{KDa} \\
\mathrm{pH} 9 \\
48{ }^{\circ} \mathrm{C}\end{array}$ & Serine protease & $\begin{array}{c}\text { High specificity } \\
\text { towards fibrin and } \\
\text { hydrolyse thrombin } \\
\text { in vitro }\end{array}$ & [113] \\
\hline $\begin{array}{l}\text { Fibrinolytic } \\
\text { enzyme }\end{array}$ & $\begin{array}{l}\text { Bacillus tequilensis } \\
\text { CWD-67 }\end{array}$ & $\begin{array}{l}22 \mathrm{KDa} \\
\mathrm{pH} 8 \\
45^{\circ} \mathrm{C}\end{array}$ & $\begin{array}{c}\text { Chymotrypsin-like } \\
\text { serine metalloprotease } \\
\text { containing hydrophobic } \\
\text { S1 pocket }\end{array}$ & $\begin{array}{c}\text { Hydrolyse } \alpha \text { chain, } \beta \\
\text { chain and finally } \gamma-{ }^{\prime} \gamma \\
\text { chain of fibrin }\end{array}$ & [192] \\
\hline BacillokinaseII & Bacillus subtilis A1 & $\begin{array}{l}31.4 \mathrm{KDa} \\
\mathrm{pH} 7 \\
50{ }^{\circ} \mathrm{C}\end{array}$ & $\begin{array}{l}\text { Chymotrypsin like } \\
\text { serine protease }\end{array}$ & $\begin{array}{l}\text { Digest fibrin as well as } \\
\text { act as plasminogen } \\
\text { activator }\end{array}$ & [193] \\
\hline $\begin{array}{l}\text { Fibrinolytic } \\
\text { enzyme }\end{array}$ & $\begin{array}{l}\text { Bacillus sp. } \\
\text { KDO-13 }\end{array}$ & $\begin{array}{l}45 \mathrm{KDa} \\
\mathrm{pH} 7 \\
60{ }^{\circ} \mathrm{C}\end{array}$ & $\begin{array}{l}\text { Metalloprotease } \\
\text { (Catalytic domain } 170 \\
\text { amino acids, hinge } \\
\text { region and hemopexin } \\
\text { domain of } 200 \text { amino } \\
\text { acids) }\end{array}$ & $\begin{array}{l}\text { Degrade fibrin or form } \\
\text { plasmin from } \\
\text { plasminogen }\end{array}$ & [185] \\
\hline $\begin{array}{l}\text { Fibrinolytic } \\
\text { enzyme }\end{array}$ & Bacillus sp. IND 7 & $\begin{array}{c}32 \mathrm{KDa} \\
\mathrm{pH} 9\end{array}$ & Serine protease & $\begin{array}{l}\text { Degrade fibrin or form } \\
\text { plasmin from } \\
\text { plasminogen }\end{array}$ & [15] \\
\hline Bafibrinase & $\begin{array}{l}\text { Bacillus sp. } \\
\text { AS-S20-I }\end{array}$ & $\begin{array}{c}32.3 \mathrm{KDa} \\
7.4 \mathrm{pH} \\
37^{\circ} \mathrm{C}\end{array}$ & $\begin{array}{l}\text { Catalytic triad made up } \\
\text { of } \mathrm{Ser}^{221}, \mathrm{His}^{64} \text { and } \\
\mathrm{Asp}^{32} \text { and have no } \\
\text { intramolecular sulphide } \\
\text { bond }\end{array}$ & $\begin{array}{c}\text { Cleave } \alpha \text { and } \beta \text { chain } \\
\text { of fibrin and } \\
\text { fibrinogen }\end{array}$ & [18] \\
\hline Subtilisin BK 17 & $\begin{array}{c}\text { Bacillus subtilis } \\
\text { BK17 }\end{array}$ & $31 \mathrm{KDa}$ & Serine protease & $\begin{array}{l}\text { Degrade fibrin or form } \\
\text { plasmin from } \\
\text { plasminogen }\end{array}$ & [194] \\
\hline $\begin{array}{l}\text { Fibrinolytic } \\
\text { enzyme }\end{array}$ & $\begin{array}{l}\text { Bacillus subtilis } \\
\text { KCK-7 }\end{array}$ & $\begin{array}{l}45 \mathrm{KDa} \\
\mathrm{pH} 7 \\
60{ }^{\circ} \mathrm{C}\end{array}$ & $\begin{array}{l}\text { Serine protease } \\
\text { requiring hydroxyl } \\
\text { group for activity }\end{array}$ & $\begin{array}{l}\text { Degrade fibrin or form } \\
\text { plasmin from } \\
\text { plasminogen }\end{array}$ & [195] \\
\hline $\begin{array}{l}\text { Douchi fibrinolytic } \\
\text { enzyme }\end{array}$ & $\begin{array}{l}\text { Bacillus subtilis LD } \\
8547\end{array}$ & $30 \mathrm{KDa}$ & Serine protease & Activate $\mathrm{t}-\mathrm{PA}$ in vivo & [14] \\
\hline $\begin{array}{l}\text { Fibrinolytic } \\
\text { enzyme }\end{array}$ & $\begin{array}{l}\text { Paenibacillus sp. } \\
\text { IND8 }\end{array}$ & - & - & $\begin{array}{l}\text { Degrade fibrin or form } \\
\text { plasmin from } \\
\text { plasminogen }\end{array}$ & [196] \\
\hline
\end{tabular}


Table 3. Cont.

\begin{tabular}{|c|c|c|c|c|c|}
\hline $\begin{array}{l}\text { Fibrinolytic } \\
\text { Enzyme }\end{array}$ & $\begin{array}{c}\text { Microbe } \\
\text { Associated }\end{array}$ & $\begin{array}{l}\text { Molecular Weight, } \\
\text { Optimal pH and } \\
\text { Temperature }\end{array}$ & Functional Moiety & Mechanism of Action & Reference \\
\hline SW 1 & $\begin{array}{l}\text { Streptomyces sp. } \\
\text { Y405 }\end{array}$ & $\begin{array}{l}\text { 30KDa } \\
\text { pH } 8\end{array}$ & $\begin{array}{l}\text { Serine protease and } \\
\text { metalloprotease }\end{array}$ & $\begin{array}{l}\text { Degrade fibrin or form } \\
\text { plasmin from } \\
\text { plasminogen }\end{array}$ & [197] \\
\hline $\begin{array}{l}\text { Fibrinolytic } \\
\text { enzyme }\end{array}$ & $\begin{array}{l}\text { Streptomyces } \\
\text { rubiginosus } \\
\text { VITPSS1 }\end{array}$ & $\begin{array}{l}45 \mathrm{KDa} \\
\mathrm{pH} 7.2 \\
32{ }^{\circ} \mathrm{C}\end{array}$ & - & $\begin{array}{l}\text { Degrade fibrin or form } \\
\text { plasmin from } \\
\text { plasminogen }\end{array}$ & [70] \\
\hline $\begin{array}{l}\text { Fibrinolytic } \\
\text { enzyme }\end{array}$ & $\begin{array}{l}\text { Streptomyces sp. } \\
\text { MCMB-379 }\end{array}$ & - & $\begin{array}{l}\text { Serine endopeptidase } \\
\text { type }\end{array}$ & $\begin{array}{l}\text { Cleaves fibrin fibres by } \\
\text { degradation of chains }\end{array}$ & [198] \\
\hline $\begin{array}{l}\beta \text { Hemolytic } \\
\text { Streptokinase }\end{array}$ & $\begin{array}{l}\text { Streptococcus } \\
\text { equinus }\end{array}$ & - & - & $\begin{array}{l}\text { Degrade fibrin or form } \\
\text { plasmin from } \\
\text { plasminogen }\end{array}$ & [40] \\
\hline $\begin{array}{l}\text { Fibrinolytic } \\
\text { enzyme }\end{array}$ & $\begin{array}{l}\text { Bacillus cereus } \\
\text { SRM-001 }\end{array}$ & $\begin{array}{l}28 \mathrm{KDa} \\
7 \mathrm{pH} \\
37^{\circ} \mathrm{C}\end{array}$ & Serine protease & $\begin{array}{l}\text { Plasmin catalysed } \\
\text { hydrolysis of fibrin }\end{array}$ & [199] \\
\hline $\begin{array}{l}\text { Fibrinolytic } \\
\text { enzyme }\end{array}$ & $\begin{array}{c}\text { Bacillus cereus IND } \\
5\end{array}$ & $\begin{array}{l}47 \mathrm{KDa} \\
8 \mathrm{pH} \\
50{ }^{\circ} \mathrm{C}\end{array}$ & Serine protease & $\begin{array}{l}\text { Degrade fibrin or form } \\
\text { plasmin from } \\
\text { plasminogen }\end{array}$ & [200] \\
\hline $\begin{array}{l}\text { Fibrinolytic } \\
\text { enzyme }\end{array}$ & Bacillus pumilus & $\begin{array}{c}20 \mathrm{KDa} \\
50{ }^{\circ} \mathrm{C}\end{array}$ & Serine protease & $\begin{array}{l}\text { Degrade } \alpha \text { and } \beta \\
\text { chains of fibrinogen } \\
\text { but not } \gamma \text { chain }\end{array}$ & [48] \\
\hline $\begin{array}{l}\text { Fibrinolytic } \\
\text { enzyme }\end{array}$ & Serratia sp. KG 2-1 & $\begin{array}{l}8 \mathrm{pH} \\
40{ }^{\circ} \mathrm{C}\end{array}$ & Metalloprotease & $\begin{array}{l}\text { Degrade fibrin or form } \\
\text { plasmin from } \\
\text { plasminogen }\end{array}$ & {$[21]$} \\
\hline $\begin{array}{l}\text { Fibrinolytic } \\
\text { enzyme }\end{array}$ & $\begin{array}{l}\text { Shewanella } \\
\text { sp. } \\
\text { IND20 }\end{array}$ & $\begin{array}{l}55.5 \mathrm{KDa} \\
8 \mathrm{pH} \\
50^{\circ} \mathrm{C}\end{array}$ & Serine protease & $\begin{array}{l}\text { Direct clot lysis and } \\
\text { plasminogen } \\
\text { activation activity }\end{array}$ & [140] \\
\hline $\begin{array}{l}\text { Fibrinolytic } \\
\text { enzyme }\end{array}$ & Cordyceps militaris & $\begin{array}{l}28 \mathrm{KDa} \\
7.2 \mathrm{pH} \\
37{ }^{\circ} \mathrm{C}\end{array}$ & Serine protease & $\begin{array}{l}\text { Activate plasminogen } \\
\text { to plasmin }\end{array}$ & [38] \\
\hline $\begin{array}{l}\text { Fibrinolytic } \\
\text { enzyme }\end{array}$ & $\begin{array}{c}\text { Lasiodiplodia } \\
\text { pseudotheobromae }\end{array}$ & $80 \mathrm{KDa}$ & - & $\begin{array}{l}\text { Degrade fibrin or form } \\
\text { plasmin from } \\
\text { plasminogen }\end{array}$ & [201] \\
\hline AMMP & Armillaria mellea & $\begin{array}{l}21 \mathrm{KDa} \\
\mathrm{pH} 6 \\
33{ }^{\circ} \mathrm{C}\end{array}$ & $\begin{array}{l}\text { Chymotrypsin-like } \\
\text { metalloprotease }\end{array}$ & $\begin{array}{l}\text { Hydrolyse } \alpha-\alpha \\
\text { fibrinogen }\end{array}$ & [39] \\
\hline $\begin{array}{l}\text { Fibrinolytic } \\
\text { enzyme }\end{array}$ & $\begin{array}{l}\text { Mucor subtilissimus } \\
\text { UCP } 1262\end{array}$ & $\begin{array}{c}20 \mathrm{KDa} \\
40{ }^{\circ} \mathrm{C}\end{array}$ & $\begin{array}{l}\text { Chymotrypsin-like } \\
\text { serine protease }\end{array}$ & $\begin{array}{l}\text { Activity is similar to } \\
\text { plasmin }\end{array}$ & [106] \\
\hline $\begin{array}{l}\text { Fibrinolytic } \\
\text { enzyme }\end{array}$ & Cochliobolus lunatus & $\begin{array}{l}\mathrm{pH} 6.8 \\
40{ }^{\circ} \mathrm{C}\end{array}$ & - & $\begin{array}{l}\text { Degrade fibrin or form } \\
\text { plasmin from } \\
\text { plasminogen }\end{array}$ & [202] \\
\hline Longolytin & Arthrobotrys longa & $\begin{array}{c}28.6 \mathrm{KDa} \\
\mathrm{pH} 6-7 \\
37^{\circ} \mathrm{C}\end{array}$ & Serine protease & $\begin{array}{l}\text { Degrade fibrin, able to } \\
\text { activate plasminogen }\end{array}$ & [176] \\
\hline $\begin{array}{l}\text { Fibrinolytic } \\
\text { protease }\end{array}$ & $\begin{array}{c}\text { Aspergillus } \\
\text { brasiliensis AUMC } \\
9735\end{array}$ & $\begin{array}{c}40 \mathrm{KDa} \\
\mathrm{pH} 8 \\
30{ }^{\circ} \mathrm{C}\end{array}$ & - & Degrade fibrin & [8] \\
\hline $\begin{array}{l}\text { Fibrinolytic } \\
\text { protease }\end{array}$ & $\begin{array}{c}\text { Aspergillus } \\
\text { brasiliensis BCW2 }\end{array}$ & $\begin{array}{l}\mathrm{pH} 7 \\
45^{\circ} \mathrm{C}\end{array}$ & - & Degrade fibrin & [101] \\
\hline
\end{tabular}


Table 3. Cont.

\begin{tabular}{|c|c|c|c|c|c|}
\hline $\begin{array}{l}\text { Fibrinolytic } \\
\text { Enzyme }\end{array}$ & $\begin{array}{c}\text { Microbe } \\
\text { Associated }\end{array}$ & $\begin{array}{l}\text { Molecular Weight, } \\
\text { Optimal pH and } \\
\text { Temperature }\end{array}$ & Functional Moiety & Mechanism of Action & Reference \\
\hline $\begin{array}{l}\text { Fibrinolytic } \\
\text { protease }\end{array}$ & $\begin{array}{l}\text { Aspergillus } \\
\text { carbonarius } \\
\text { S-CSR-0007 }\end{array}$ & $\begin{array}{l}\mathrm{pH} 7 \\
45^{\circ} \mathrm{C}\end{array}$ & - & Degrade fibrin & [31] \\
\hline $\begin{array}{l}\text { Fibrinolytic } \\
\text { protease }\end{array}$ & $\begin{array}{c}\text { Aspergillus } \\
\text { fumigatus CBS } \\
113.26\end{array}$ & $\begin{array}{c}35 \mathrm{KDa} \\
\mathrm{pH} 9 \\
37-42{ }^{\circ} \mathrm{C}\end{array}$ & Serine protease & Degrade fibrinogen & [100] \\
\hline $\mathrm{AO}-3$ & $\begin{array}{c}\text { Aspergillus } \\
\text { ochraceus VKM } \\
\text { F-4104D }\end{array}$ & $\begin{array}{l}35 \mathrm{KDa} \\
\mathrm{pH} 9 \\
45{ }^{\circ} \mathrm{C}\end{array}$ & Serine protease & Degrade fibrin & [20] \\
\hline Terrilytin & Aspergillus terricola & $\begin{array}{l}27 \mathrm{KDa} \\
\mathrm{pH} 6.5 \\
53{ }^{\circ} \mathrm{C}\end{array}$ & Serine protease & Degrade fibrin & [19] \\
\hline $\begin{array}{l}\text { Fibrinolytic } \\
\text { protease }\end{array}$ & Aspergillus ustus 1 & $\begin{array}{l}33 \mathrm{KDa} \\
\mathrm{pH} 6 \\
41^{\circ} \mathrm{C}\end{array}$ & Serine protease & Degrade fibrin & {$[30]$} \\
\hline $\begin{array}{l}\text { Fibrinolytic } \\
\text { protease }\end{array}$ & $\begin{array}{c}\text { Aspergillus flavus } \\
\text { O-1 }\end{array}$ & $17 \mathrm{KDa}$ & Serine protease & Degrade fibrin & [32] \\
\hline FP & Fusarium sp. BLB & $\begin{array}{l}27 \mathrm{KDa} \\
\mathrm{pH} 9.5 \\
50{ }^{\circ} \mathrm{C}\end{array}$ & Serine protease & Degrade fibrin & [180] \\
\hline $\mathrm{Fu}-\mathrm{P}$ & $\begin{array}{l}\text { Fusarium sp. } \\
\text { CPCC } 480097\end{array}$ & $\begin{array}{c}28 \mathrm{KDa} \\
\mathrm{pH} 8.5 \\
45^{\circ} \mathrm{C}\end{array}$ & $\begin{array}{l}\text { Chymotrypsin-like } \\
\text { serine metalloprotease }\end{array}$ & $\begin{array}{l}\text { Cleaved the } \alpha \text {-chain of } \\
\text { fibrin (ogen) with high } \\
\text { efficiency, and the } \\
\beta \text {-chain and } \gamma \text { - } \gamma \\
(\gamma-) \text {-chain with lower } \\
\text { efficiency }\end{array}$ & [104] \\
\hline $\begin{array}{l}\text { Fibrinolytic } \\
\text { protease }\end{array}$ & Neurospora sitophila & $\begin{array}{l}49 \mathrm{KDa} \\
\mathrm{pH} 7.4 \\
50{ }^{\circ} \mathrm{C}\end{array}$ & $\begin{array}{l}\text { Chymotrypsin-like } \\
\text { serine protease }\end{array}$ & $\begin{array}{l}\text { Degrade all chains of } \\
\text { fibrinogen }\end{array}$ & [63] \\
\hline $\begin{array}{l}\text { Fibrinolytic } \\
\text { protease }\end{array}$ & $\begin{array}{l}\text { Oidiodendron } \\
\text { flavum }\end{array}$ & $\begin{array}{l}22 \mathrm{KDa} \\
\mathrm{pH} 8 \\
45^{\circ} \mathrm{C}\end{array}$ & - & Degrade fibrin & [107] \\
\hline PTEFP & $\begin{array}{l}\text { Paecilomyces } \\
\text { tenuipes }\end{array}$ & $\begin{array}{l}14 \mathrm{KDa} \\
\mathrm{pH} 5 \\
35{ }^{\circ} \mathrm{C}\end{array}$ & - & $\begin{array}{l}\text { Degrade } A \alpha \text {-chain of } \\
\text { human fibrinogen but } \\
\text { did not hydrolyse } B \beta- \\
\text { or } \gamma \text {-chain }\end{array}$ & {$[56]$} \\
\hline $\begin{array}{l}\text { Fibrinolytic } \\
\text { protease }\end{array}$ & $\begin{array}{c}\text { Rhizopus chinensis } \\
12\end{array}$ & $\begin{array}{c}16.6 \mathrm{KDa} \\
\mathrm{pH} 10.5 \\
45^{\circ} \mathrm{C}\end{array}$ & $\begin{array}{l}\text { Serine protease and } \\
\text { metalloprotease }\end{array}$ & $\begin{array}{l}\text { Degrade fibrin and } \\
\text { fibrinogen }\end{array}$ & [58] \\
\hline $\begin{array}{l}\text { Fibrinolytic } \\
\text { protease }\end{array}$ & $\begin{array}{c}\text { Rhizopus } \\
\text { microsporus var. } \\
\text { tuberosus }\end{array}$ & $\begin{array}{c}24.5 \mathrm{KDa} \\
\mathrm{pH} 7 \\
37^{\circ} \mathrm{C}\end{array}$ & - & $\begin{array}{l}\text { Degrade fibrin and } \\
\text { activate plasminogen }\end{array}$ & [62] \\
\hline Proteinase III & $\begin{array}{l}\text { Sarocladium } \\
\text { strictum }\end{array}$ & $\begin{array}{l}35 \mathrm{KDa} \\
\mathrm{pH} 10 \\
30{ }^{\circ} \mathrm{C}\end{array}$ & Serine protease & $\begin{array}{l}\text { Degrade fibrin and } \\
\text { activate plasminogen }\end{array}$ & {$[64]$} \\
\hline $\begin{array}{l}\text { Fibrinolytic } \\
\text { protease }\end{array}$ & $\begin{array}{l}\text { Scedosporium } \\
\text { apiospermum }\end{array}$ & $\begin{array}{l}33 \mathrm{KDa} \\
\mathrm{pH} 9 \\
37^{\circ} \mathrm{C}\end{array}$ & $\begin{array}{l}\text { Subtilisin-like serine } \\
\text { protease }\end{array}$ & Degrade fibrinogen & [110] \\
\hline
\end{tabular}




\section{Structural-Functional Attributes}

An evaluation of structural-functional characteristics and mechanisms of action is imperative for the massive applicability (industrial/therapeutic) of enzymes [24,203]. However, literature reports limited research on structural-functional attributes and intermolecular interactions of fibrinolytic enzymes [24]. In a recent study, homology structural modelling servers Iterative threading ASSEmbly Refinement (I-TASSER), RaptorX, Protein Homology/analogY Recognition Engine V 2.0 (Phyre2) and SWISS-MODEL were used to model a three-dimensional (3D) structure of fibrinolytic protease RFEA1 from Bacillus cereus RSA1, and structural validation was accomplished by structural analysis and verification server (SAVES v6.0). In addition, structural modelling revealed the presence of a high-affinity calcium binding site (Ca1), associated with hydrogen bonds at Asp ${ }^{147}$, $\mathrm{Leu}^{181}$, $\mathrm{Ile}^{185}$ and Val ${ }^{187}$ RFEA1 residues. Furthermore, an enzyme-substrate docked complex (RFEA1-fibrin) exhibited a high binding affinity $(-21.36 \mathrm{kcal} / \mathrm{mol})$, suggesting the significant activity/specificity of enzyme and serine (subtilisin) catalytic residues were observed (Asp ${ }^{146}$, Ser ${ }^{164}$ and His ${ }^{132}$ ) [24]. Subtilisin enzymes have high-affinity (Ca1) and low-affinity (Ca2) calcium binding sites which play vital roles in the thermostability of enzymes and prevent autolysis. Enhanced thermostability due to the presence of calcium binding sites was reported for Bacillus subtilis HK176 produced fibrinolytic enzymes (AprE176: 11\% and M179: 36\%) [119], while a significant activity increase (122.02 $\pm 5.71 \%)$ was observed for Bacillus subtilis DC27 produced fibrinolytic enzyme in the presence of 5 $\mathrm{mM} \mathrm{Ca}^{2+}$ ions [2]. Another study reported on the I-TASSER modelled structure of a serine fibrinolytic protease Bacifrinase which entailed the catalytic triad of $\mathrm{Asp}^{102}$, $\mathrm{His}^{83}$ and $\mathrm{Ser}^{195}$. The bacifrinase-fibrinogen (B $\beta$-chain) interaction was stable with a geometric shape complementarity score of 19698, interface area of 2522.80 and ACE of 442.39 [28]. Further, the SWISS-MODEL predicted a 3D structure of subtilisin K2 when it underwent docking using the High Ambiguity Driven protein-protein DOCKing (HADDOCK) webserver against substrate fibrin and showed a Kd value of $6.3 \cdot 10^{-15} \mathrm{M}$ and binding affinity of $19.4 \mathrm{kcal} / \mathrm{mol}$. Structural superimposition of subtilisin K2 on nattokinase generated a root mean square deviation of $0.12 \AA$ and indicated a significant similarity between the two proteins. However, the positions of active site residues of subtilisin $\mathrm{K} 2\left(\mathrm{Asp}^{19}, \mathrm{His}^{51}\right.$, and $\mathrm{Ser}^{208}$ ) were dissimilar from nattokinase active site residues $\left(\mathrm{Asp}^{32}\right.$, $\mathrm{His}^{64}$, and $\mathrm{Ser}^{221}$ ) [49]. A detailed list of the structural-functional attributes of microbial fibrinolytic enzymes is listed in Table 4.

Table 4. Structural-functional characteristics of microbial fibrinolytic enzymes.

\begin{tabular}{|c|c|c|c|c|c|}
\hline Origin of Enzyme & $\begin{array}{l}\text { Structural } \\
\text { Prediction }\end{array}$ & Docking Tools & $\begin{array}{l}\text { Substrate/Binding } \\
\text { Affinity/Score }\end{array}$ & $\begin{array}{l}\text { Active Sites/ } \\
\text { Interacting } \\
\text { Residues }\end{array}$ & References \\
\hline $\begin{array}{l}\text { Bacillus subtilis } \\
\text { S127e }\end{array}$ & I-TASSER & - & - & $\begin{array}{c}\mathrm{Asp}^{32}, \mathrm{His}^{64} \text { and } \\
\text { Ser }^{221}\end{array}$ & [204] \\
\hline $\begin{array}{l}\text { Bacillus cereus } \\
\text { RSA1 }\end{array}$ & $\begin{array}{c}\text { I-TASSER, } \\
\text { Swiss-Model, } \\
\text { RAPTORX and } \\
\text { Phyre2 }\end{array}$ & $\begin{array}{l}\text { PATCHDOCK and } \\
\text { FIREDOCK }\end{array}$ & $\begin{array}{l}\text { Substrate: Fibrin } \\
\text { Affinity: }-21.36 \\
\text { kcal/mol }\end{array}$ & $\begin{array}{c}\text { Asp } \\
\text { His }^{146}, \text { Ser }^{164} \text { and }\end{array}$ & {$[24]$} \\
\hline $\begin{array}{l}\text { Bacillus cereus } \\
\text { AB } 01\end{array}$ & I-TASSER & PATCHDOCK & $\begin{array}{l}\text { Substrate: Fibrinogen } \\
\text { Dock score: } 19698\end{array}$ & $\begin{array}{c}\text { Asp }^{102}, \mathrm{His}^{83} \text { and } \\
\text { Ser }^{195}\end{array}$ & [28] \\
\hline Bacillus subtilis K2 & SWISS-MODEL & HADDOCK & $\begin{array}{c}\text { Substrate: Fibrin } \\
\text { Affinity: }-19.4 \\
\text { kcal/mol }\end{array}$ & $\begin{array}{c}\text { Asp }^{19}, \operatorname{His}^{51} \text { and } \\
\text { Ser }^{208}\end{array}$ & [49] \\
\hline Bacillus natto & MODELLER & AUTODOCK & $\begin{array}{c}\text { Substrates: } \\
\text { H-D-VLK-pNA and } \\
\text { SucAAPF-pNA }\end{array}$ & $\begin{array}{c}\mathrm{Asp}^{32}, \mathrm{His}^{64} \text { and } \\
\text { Ser }^{221}\end{array}$ & [205] \\
\hline
\end{tabular}


Table 4. Cont

\begin{tabular}{ccccc}
\hline Origin of Enzyme & $\begin{array}{c}\text { Structural } \\
\text { Prediction }\end{array}$ & Docking Tools & $\begin{array}{c}\text { Substrate/Binding } \\
\text { Affinity/Score }\end{array}$ & $\begin{array}{c}\text { Active Sites/ } \\
\text { Interacting } \\
\text { Residues }\end{array}$ \\
\hline $\begin{array}{c}\text { Bacillus subtilis } \\
\text { natto }\end{array}$ & X-ray diffraction & - & - & - \\
\hline $\begin{array}{c}\text { Bacillus subtilis sp. } \\
\text { natto }\end{array}$ & Geno3D2 & - & - & - \\
\hline Bacillus sp. & $\begin{array}{c}\text { Protein Data Bank: } \\
\text { PDB (4DWW) }\end{array}$ & HADDOCK & $\begin{array}{c}\text { Substrate: Fibrinogen } \\
\text { Dock Score: }-114.3 \pm \\
4.7\end{array}$ & $\begin{array}{c}\mathrm{Gly}^{61}, \mathrm{Ser}^{63}, \mathrm{Thr}^{99}, \\
\mathrm{Phe}^{189}, \mathrm{Leu}^{209}, \\
\mathrm{Tyr}^{217}, \mathrm{Asn}^{218} \mathrm{and}^{2} \\
\mathrm{Met}^{222}\end{array}$ \\
\hline
\end{tabular}

\section{Thrombolytic Potential of Microbial Fibrinolytic Enzymes}

In vitro and in vivo estimation of the thrombolytic potential of fibrinolytic enzymes significantly aid in their potential use in clinical practices and hence commercialisation. There are varieties of methods proposed to access the in vitro anti-thrombotic potential of enzymes using blood and its elements, which provide indispensable inputs before animal modelled studies [209].

\subsection{In Vitro Fibrinolytic Assays}

There are numerous methodologies adopted for the assessment of the clot lysing potential of enzymes, for example, fibrin plate assay, fibrin micro-plate assay, rapid fibrin plate assay, euglobulin clot lysis time, global fibrinolytic capacity and viscoelastic methods, etc. [210-215]. Fibrin/clot lysis outcome in such methods is generally measured by evaluating the zone of hydrolysis, calorimetric methods and nephelometry $[5,216,217]$. Our review enlightens different assays used by researchers in detail. The fibrin plate assay is a delicate and detailed process for determining fibrinolytic mediators. The assay comprises of either fibrin clot as a substrate (formed by the addition of thrombin to fibrinogen) or fibrin directly. It is usually performed in two systems. The first being the 'plasminogen free fibrin plate assay', is entitled for the direct action of plasmin-like enzymes. Endogenous fibrinolytic factors such as plasminogen and plasmin are deactivated at high temperature conditions (mostly $80^{\circ} \mathrm{C}$ for $30-45 \mathrm{~min}$ ) [5]. The second is 'plasminogen rich fibrin plate assay', which is not exposed to extreme temperature conditions and is suitable for plasminogen activators [16]. A certain amount of difficulty and uncertainty in determining the lysis zone was observed in fibrin plate assay and to overcome this problem fibrin micro-plate assay was developed. It is a high capacity sensitive and quantitative fibrinolytic micro-technique in which fibrin clots are moulded in wells of immense adsorption microtiter plates with suitable dye integrated into them with the help of fibrinogen. For reference, serial dilutions of urokinase/plate (standard) are added into these microtiter plates. Inhibitors are removed from citrated test plasmas before their application into the wells through acetone treatment. After suitable incubation, the lysate formed is discarded and fibrin is photometrically determined after dissolution by plasmin. The advantage associated with this assay is the reliable degree of clot lysis assessment by adjusting incubation time and varying concentration of standard urokinase [218].

A long incubation period was the major drawback of fibrin plate assay which was improved by rapid fibrin plate assay carried out to inspect plasminogen enrichment. In a study conducted by Marsh and Gaffney, fibrin plates were modified by the addition of two casein units of plasminogen to form firm and opaque plates for clarity. The clots formed did not lyse impulsively and yielded effective parallel lines for urokinase and streptokinase after an incubation period of $3 \mathrm{~h}$ instead of 16-20 h [212]. Another in vitro euglobulin clot lysis time (ECLT) assay is used to evaluate plasma fibrinolytic capacity and signifies the interaction of activity amongst the tissue plasminogen activator and 
plasminogen activating inhibitor [219]. It measures the change in optical density of the recalcified euglobulin fraction present in plasma samples over different time intervals [213]. A quantitative ECLT assessment is performed by a microtiter plate reader providing reliable and reproductive data where lysis time is determined by the midpoint between minimum and maximum turbidity. The turbidity is measured by the microtiter plate reader after every $30 \mathrm{~min}$. Its mathematical examination not only determines critical points of lysis curvature but also analyses kinetics of fibrinolysis. It is used for determining hyperlipemic condition, atherosclerosis and its associated diseases, cardiovascular surgery, pharmacological surgery and liver transplantation coagulation surgery. Global fibrinolytic capacity (GFC) is used to analyse single sample, evaluating fibrinolysis by generation of D-dimers (DD) from the fibrin clot [219]. In this assay, the fibrin clot was prepared with plasminogen free fibrinogen and thrombin. It was allowed to freeze dry and used to make fibrin tablets $(25 \mu \mathrm{g})$ with silica. These tablets were added to tubes containing platelets poor plasma and tPA. After incubation at $37^{\circ} \mathrm{C}$ for one-hour, the fibrinolytic process was reduced by the accumulation of aprotinin and the generation of D- dimers were measured [209]. It is an expensive assay due to the DD evaluation and reagents used [219]. GFC is used to estimate fibrinolysis activity (plasma) in various conditions such as diabetes type I and II, sepsis, polycystic ovary syndrome, chronic liver disease, mitral valve disease, respiratory distress syndrome and hypothyroidism [209].

However, the above-mentioned traditional approaches of thrombolysis assessment encompass direct experimental manual handling, which might introduce errors and thus limit precision. In such cases, rheology methods (thromboelastometry, thromboelastography and sonoclot) based on the viscoelastic properties of blood clot formation and dissolution are employed. Viscoelastic methods are used to analyse clotting and fibrinolytic processes in whole blood and examine the influence of blood cells and platelets. The major advantages associated are: speed and the important role in point of care tests (POC) during surgical procedure related to blood loss, liver transplant, traumatic injury and cardiothoracic surgery [220]. The first method 'thromboelastometry (ROTEM)' computes the viscoelastic properties of clot, kinetics of clot growth, provides data on speed of coagulation commencement, clot firmness and breakdown [221]. It involves differential testing on one patient using four channels. This testing involves Intem (Intrinsic coagulation with ellagic acid), Extem (Factor triggering extrinsic activators), Fibtem (Cytochalasin D added to Extem to eliminate platelet role) and lastly Aptem (Aprotinin added to Exten to stop fibrinolysis). Temograms are used to display all results of clotting and lysis curves [220]. Different parameters such as clotting time in seconds, amplitude 10 (clot amplitude $10 \mathrm{~min}$ after the commencement of the clotting in $\mathrm{mm}$ ) and maximal clot firmness ( $\mathrm{mm}$ ) can be recorded from ROTEM tests. The second 'thromboelastography (TEG)' involves various tests possessing differential reagents such as kaolin instead of ellagic acid in Intem [220]. It can quickly determine low coagulation, hypercoagulation or solidification to fibrinolysis (involving prothrombin, thrombin, fibrin formation, stability and elasticity of blood clot) in the patient's blood directly. TEG involves the Estimated Percentage of Lysis (EPL) or Lysis at $30 \mathrm{~min}$ (LY30) [222]. TEG and ROTEM analysers evaluate the actual properties of a clot by the use of an immobile cylindrical cup holding the citrated whole blood and calcium chloride with specific activators and oscillating at an angle of $4^{\circ}-45^{\circ}$. Each rotation cycle persists for $10 \mathrm{~s}$. A pin is suspended vertically in the blood through a torsional wire and is supervised according to the motion. The torque of the revolving cup is conveyed to the submerged pin only after the fibrin platelet bonding links the cup and pin together. The magnitude of the pin motion is affected by the bonding of these fibrin platelets. Hence, the strength of the fibrin platelet is directly linked with the magnitude of the output. When these clots are broken down during lysis the cup motion is reduced. The rotational motion of the pin is transformed by an automatic electrical transducer to an electrical signal leading to a graphical display (plot showing viscoelastic properties of the clot over time) which is supervised by a computer [221,222]. The third alternative 'sonoclot' measures the change in resistivity to the movement on a small probe pulsating at an ultrasonic frequency in a 
coagulating blood sample. The resistivity is induced by the emerging clot. An open ended, hollow disposable plastic probe mounted on an ultrasonic transducer which trembles vertically at a rate of $100 \mathrm{~Hz}$ (distance of $1 \mu \mathrm{m}$ ) is submerged in a cuvette comprising blood sample $(0.4 \mathrm{~mL})$ at fixed depth. The cuvette applies a viscous drag on the probe and this dragging force upsurges as the sample clots. Fibrin components form on the tip of the probe and between the probe and wall of the cuvette, eventually enhancing the mass of the probe. This increase in resistivity to the vibration of the probe due to the clotting of the sample is sensed via electronic circuits which are then transformed to an output signal on a paper chart plotter reflecting the viscoelastic properties of the clot. This unceasing output signal describes the blood coagulation process starting from fibrin development, aggregation of fibrin monomers, platelet interaction, clot retraction and lastly lysis [223].

Nevertheless, these viscoelastic techniques also have limitations such as insufficient equipment accessibility, number of tests executed at a time (extreme four samples) and required sample (whole blood) size $(300 \mu \mathrm{L})$. Therefore, researchers have developed and suggested a high throughput whole blood thrombolysis plate assay to overcome the limitations of existing techniques. The halo assay technique by Bonnard et al. includes the formation of halo shaped, tissue factor prompted, whole blood clots in 96-well plates. The clot lysis rate using different doses of plasmin, urokinase and tissue plasminogen activator (t-PA) was determined with a spectrophotometer plate reader. Results revealed that plasmin directly acted on halo-clots with a short activation time whereas t-PA displayed a distinct lysis protocol, which might be due to the conversion of endogenous plasminogen into plasmin and then fibrin degradation. The activation time was significantly delayed with urokinase, and the utmost rate of clot degradation was reduced on aged clots. The technique overcomes limitations by a considerable reduction in the required volume of blood and imparting high throughput screening on a whole blood-based assay. Furthermore, the methodology discovered could significantly be transformed to clinical practices as a pointof-care assay to upgrade the diagnosis of cardiovascular disorders [224]. Such techniques have also been used for the evaluation of the thrombolytic potential of thrombin-activatable microplasminogen and thrombin-degradable capsules $[225,226]$.

\subsection{In Vivo Thrombolytic Assays}

An in vivo/animal modelled study is an essential step to comprehend the pathophysiology of cardiovascular thrombosis and function as an efficient platform to assess novel therapeutics for the prevention and cure of thrombolytic complications. The fibrinolytic enzymes under in vivo examination are either administered intravenously or as oral anti-coagulants. Our review discusses details of all reported in vivo models, both based on thrombus initiation/lysis and indirect measurement of fibrinolysis (D-dimer test, carrageenan-induced thrombosis model, ferric chloride-induced thrombosis model, laser-induced and phytochemical injury).

The first ' $\mathrm{D}$-dimer assay' monitors fibrin lysis by detecting the presence of D-dimer fragments released in mammalian blood by immunoassays (immunoturbidimetry, latex agglutination and enzyme-linked immunosorbent assay) with monoclonal antibodies specific for D-dimer domain. It determines the duration of anti-coagulation therapy and is expressed in mass units: D-dimer unit (DDU) at $195 \mathrm{kDa}$ and fibrinogen equivalent unit (FEU) at $340 \mathrm{kDa}$ [227]. The test is employed during pulmonary embolism, arterial and venous thromboembolism [228-230] but lacks in reproducibility, non-applicability for fibrinogenolysis (as D-domain is not present in derivatives of fibrinogen) and variation in type/magnitude of D-dimer units which leads to confusion [227]. Further, the comparatively reliable carrageenan-induced thrombosis model has been extensively employed for testing of numerous anti-thrombotic agents clinically [14,75,231-234]. Carrageenan is a mucopolysaccharide obtained from edible red seaweeds, encompassed by repeating units of sulphated/nonsulphated anhydrogalactose and galactose connected by glycosidic linkages. On the basis of the different positions/numbering of sulphur groups on galactose units, three carrageenan classes, kappa, iota and lambda carrageenan are available [235]. 
However, k-carrageenans (kappa) were stated to be of the utmost significance [236] and were used in the majority of the experiments $[13,75,234,237]$. The thrombolytic agent to be tested is injected intraperitoneally followed by intravenous injection of sterilized carrageenan and thereafter, animal tail is submerged in ice water to observe the appearance/dissolution of a wine-coloured clot [233]. Major advantages associated with the use of this model include: precise evaluation of thrombus dissolution and drug efficacy, need of fewer animals without killing them and evading of complex surgery exposing blood vessels in animal tails. Additionally, k-carrageenan may impact the deactivation of Hageman factor [238], which is followed by endogenous coagulation [239].

The ferric chloride-induced thrombosis model has also been extensively used to assess the in vivo efficacy of anti-platelet drugs and anti-coagulants $[14,239,240]$. Intravascular thrombus is introduced by the application of ferric chloride into an intact vessel (for example: carotid artery) [14] and the effectiveness of the test compound is examined. The thrombolytic agent which is to be tested is introduced intraperitoneally into the vessel followed by a ferric chloride solution. Doppler flowmeter reflecting the occlusion time is used to monitor the blood flow in the vessel. In addition, observations can be studied using intravital microscopy as well. The time period from the initial injury to complete vessel destruction is the measured parameter [241]. The clot formation induced into the vessel is closest to the human pathological condition and is a major merit associated with this assay. Furthermore, the model is sensitive to various thrombin inhibitors, representing its reliability for in vivo assays. However, diagnosis and treatment of deep vein thrombosis (DVT) must be performed in combination with other assays as the entire vessel injury predicts a lesser number of DVT [242]. In fact, alternative strategies for in vivo thrombus formation such as laser-induced and phytochemical injury have also been employed in most studies to determine the thrombolytic potential of the test compound. The laserinduced injury model is based on the induction of thrombus through heat damage to a defined endothelium section [243], whereas, in a phytochemical injury a photosensitizing dye (for example: rose bengal) is used, which causes photo-excitation and leads to oxidative damage to the wall of the blood vessel, ultimately resulting in thrombus formation. The thrombolytic agent to be tested is administered prior to thrombus formation in both the mentioned models. Advantages associated are: (i) the damage caused to endothelium by laser-induced injury is more limited than the ferric-chloride induced method which results in the complete denudation of endothelium [243], (ii) lower systemic toxicity and increased phytochemical efficacy are added merits of the phytochemical injury technique [244].

Moreover, the thrombolytic effect of nattokinase has been investigated on clots introduced by acetic acid injury in the carotid artery of a rat. A $62 \%$ recovery rate of arterial blood flow was observed in rats treated with nattokinase in comparison to plasmin with $15.8 \%$ recovery and elastase with no recovery [245]. Oral administration of nattokinase has been investigated and clinically tested in both animal and human trials. Research testifies the efficacy/stability of nattokinase in mammalian digestive tracts with continued action (8-12 h) and the prevention of thrombus formation with an oral daily dose of nattokinase ( $2000 \mathrm{FU}$ or $50 \mathrm{~g}$ ) [12]. In another study by Sumi et al. in 1990, the oral administration of four capsules of nattokinase completely dissolved blood clots (within $5 \mathrm{~h}$ ) administered in the leg vein of dogs [246]. Human trial with 12 healthy participants when administered with $200 \mathrm{~g} /$ day of nattokinase enhanced the blood clot dissolution ability of volunteers even after $2-8 \mathrm{~h}$ of administration [22]. Urano et al. reported the ability of nattokinase in the cleavage of PAI-1 (primary fibrinolysis inhibitor) [247]. Henceforth, several microbial fibrinolytic agents have been subjected to in vivo animal/human trials to this day.

\section{Other Miscellaneous Applications of Microbial Fibrinolytic Enzymes}

Along with clot lysis efficacy, microbial fibrinolytic enzymes have been reported to exhibit many other miscellaneous applications in clinical, industrial and food sectors such as blood pressure regulation, proteolysis in addition to fibrin, detergent additives, 
antimicrobials and anti-inflammatory agents, etc. A detailed review of reported prodigious applications of microbial fibrinolytic enzymes is discussed below.

\subsection{Microbial Fibrinolytic Enzymes in Clinical Practices and Food Sector}

A recent in vivo study conducted on rats reported the use of nattokinase-like enzyme (NK-01) in thrombosis along with the reduction of blood pressure and prevention of atherosclerosis. Label-free liquid chromatography-tandem mass spectrometry technique was employed to examine NK-01 effects on the proteomic profiling of plasma proteins. NK-01 inhibited angiotensinogen translation to AngII, thus promoting kininogen lysis to control blood pressure. The protease was also said to increase the amount of paraoxonase 1 to thwart atherosclerosis [248]. Kim et al. also performed a randomised human trial to study the effects of nattokinase on blood pressure/hypertension. A total of 86 volunteers (20 to 80 years) with systolic blood pressure $(130$ to $159 \mathrm{mmHg}$ ) were fed with nattokinase (2000 FU/capsule) for 8 weeks. The outcome confirmed that the intake of nattokinase resulted in reducing systolic and diastolic blood pressure [249]. Oral administration of nattokinase and serrapeptase is reported to show a protective effect against Alzheimer's disease [250]. Enzyme serrapeptase is stated to have potent anti-inflammatory and other beneficial properties along with thrombolytic activity $[6,16,251,252]$. Panagariya and Sharma examined the response of serrapeptase in patients with carpal tunnel syndrome (CTS). Twenty patients were administered with serratiopeptidase (10 $\mathrm{mg}$ twice/daily) and results were evaluated after 6 weeks. Significant improvements in sixty-five percent of cases without any after-effects were observed [253]. The efficacy of serrapeptase has also been tested and confirmed in the treatment of venous inflammatory disease, antiedemic activity, inflammation in patients with breast engorgement, chronic airway diseases (decreased neutrophil count, sputum output and viscosity) and chronic sinusitis, etc. [254-257]. In another in vivo animal trial, serrapeptidase was found effective against Staphylococcus epidermidis in the abolition of infection with increased antibiotic efficacy [258]. Furthermore, in a study conducted in men with amicrobial prostato-vesiculitis, serrapeptidase along with other anti-inflammatory drugs efficiently reduced the swelling of prostate glands [259]. An amino acid sequence of Ace02 (fibrinolytic enzyme from B. vallismortis Ace02) exhibited strong sequence similarity with L27 (bacteriolytic enzyme from B. licheniformis), which has potent lytic potential against the pathogen of dental caries (Streptococcus mutans), thus suggesting its use for the prevention of dental caries along with thrombosis [260].

$\mathrm{Wu}$ and $\mathrm{Xu}$ reported that fibrinolytic protease of Fusarium sp. CPCC 480097 (Fu-P) in a rat model of artery-vein bypass thrombosis might also be used as a natural agent for thrombolytic therapy or thrombosis prevention [53]. The intravenous injection of Fu$\mathrm{P}$ produced a $58.4 \%$ inhibition ratio of thrombus formation at $0.1 \mathrm{mg} / \mathrm{kg}$ body weight, compared with heparin which produced a $42.5 \%$ inhibition ratio of thrombus formation at $0.6 \mathrm{mg} / \mathrm{kg}$ body weight. Fu-P also significantly prolonged fibrinogen clotting time, activated partial thromboplastin time and thrombin time. It was shown that the protease was not the inhibitor of the thrombin and Xa [53]. Another fungal fibrinolytic protease of Mucor subtilissimus UCP 1262 was tested in the experiments on Mus musculus and can be regarded as a potential competitor for developing novel anti-thrombotic drugs. The assay to assess blood biocompatibility shows that at a dose of $0.3-5 \mathrm{mg} / \mathrm{mL}$ the haemolytic grade is considered insignificant. It was shown that this enzyme did not prolong bleeding time in mice when dosed with $1 \mathrm{mg} / \mathrm{kg}$ [52].

Fibrinolytic enzymes have also been reported with a momentous role in food fortification and nutraceutical applications, suggesting their use in reducing the risk of cardiovascular diseases [261]. A novel fibrinolytic enzyme from fermented shrimp paste (Asian fermented seasoning) was reported with significant potential for food fortification and nutraceutical applications along with its use in thrombolytic therapy [178]. Fibrinolytic alkaline protease KSK-II from Lactobacillus plantarum KSK-II was found to inhibit the growth of S. aureus $(29 \%)$, B. cereus ( $21 \%)$, P. aeruginosa $(13 \%)$, P. vulgaris $(10 \%)$, E. coli $(7 \%)$ and K. pneumonia (0\%). The anti-fungal activity of KSK-II was observed against Rhizoctonia 
solani (soilborne plant pathogen) [187]. Such proteases are applied as anti-microbials for wall perforation to release endogenous metabolites [262] and in food and medical applications [263].

\subsection{Industrial Applications of Microbial Fibrinolytic Enzymes}

Some fibrinolytic enzymes exhibit a wide spectrum for proteolysis in addition to fibrin. KSK-II (fibrinolytic enzyme from L. plantarum) was found to hydrolyse plasma proteins along with collagen and fibrin. This attribute of KSK-II prohibited its use in in vivo thrombus hydrolysis as the action of enzyme on haemoglobin and collagen might lead to haemorrhage. KSK-II was also compatible and stable with detergent formulations Persil $(112 \%)$, X-tra $^{\circledR}(98 \%)$, Ariel ${ }^{\circledR}(92 \%)$, Tide $^{\circledR}(86 \%)$, Lang $^{\circledR}(81 \%)$, Dac $^{\circledR}(80 \%)$, Isis ${ }^{\circledR}$ $(77 \%)$, Bonux $^{\circledR}(75 \%), \operatorname{Dixan}^{\circledR}(67 \%)$ and Oxi ${ }^{\circledR}(64 \%)$. Optimal pH and temperature of the enzyme was $\mathrm{pH} 10.0$ and $50{ }^{\circ} \mathrm{C}$ with wide stability at $\mathrm{pH} 7.5-12.0$ and up to $70{ }^{\circ} \mathrm{C}$. Thus, the enzyme was considered a suitable detergent additive [187]. Masilamani and Natarajan reported a fibrinolytic enzyme from Marinobacter aquaeolei MS2-1 with significant activities with detergents Ujala, Tide, Wheel, Surf, Excel and Kite and maximum enzyme activity with Rin [264]. An increase in activity (up to 141\%) of a detergent-resistant nattokinase from B. subtilis VTCC-DVN-12-01 was observed with non-ionic detergents (Tween-20, Tween-80 and Triton X-100) [116]. A fibrinolytic enzyme from Bacillus sp. IND12 hydrolysed egg white, chicken skin, goat blood clot and bovine serum albumin, which recommended its use in both clinical practices and wastewater treatment [130]. Henceforth, microbial fibrinolytic enzymes with blood clot dissolution efficiency might be explored for potential applications in industrial sectors as well.

\section{Conclusions}

In conclusion, our review discusses in detail the diverse sources, optimisation techniques, production (isolates and mutants/recombinants), in vitro/in vivo thrombolytic trials and tremendous possibilities of microbial fibrinolytic enzymes towards therapeutic (blood clot removal/treatment of cardiovascular thrombosis) and food/detergent industry deployment. The high efficacy/specificity of fibrinolytic enzymes from fermented foods like Chungkook-jang, Dosa, Douche, Doen-jang, Jeot-gals, Gembus, Kishk, Moromi, etc., was observed, when equated with other sources (culture collections, milk, soil samples or marine isolates). Furthermore, techniques such as the construction of genetically modified strains, molecular cloning/overexpression and mutated sources significantly enhanced the fibrinolytic potential, specificity/stability and scale up of the enzymes. Optimal production of enzymes was achieved through statistically optimised media, thus eradicating the enormous substrate cost and time. Most of the fibrinolytic enzymes have been successfully purified and characterised to evaluate their physiochemical properties, functional moiety and mechanism of action. Furthermore, in vitro and in vivo studies of thrombolytic assays alone or in combinations have detailed the clinical effectiveness and safety of enzymes, alleviating the comprehensive pathophysiology of thrombosis in mammals. In addition, surplus applications such as blood pressure regulation, anti-microbial/anti-inflammatory potential, detergent additives, etc., of some fibrinolytic enzymes are reported. However, the mechanism behind the aforementioned applications is so far uncertain.

Author Contributions: Writing-Original draft preparation, C.S.; Writing-Review and editing, C.S., R.S. and A.O.; Supervision, R.S. and A.O. All authors have read and agreed to the published version of the manuscript.

Funding: The APC was funded by Financial Council for Grants of the President of the Russian Federation No. SP-3906.2021.4.

Institutional Review Board Statement: Not applicable.

Informed Consent Statement: Not applicable.

Data Availability Statement: All data are available in the main text. 
Conflicts of Interest: The authors declare no conflict of interest.

\section{References}

1. Koene, J.R.; Prizment, A.E.; Blaes, A.; Konety, S.H. Shared risk factors in cardiovascular disease and cancer. Circulation 2016, 133, 1104-1114. [CrossRef] [PubMed]

2. Hu, Y.; Yu, D.; Wang, Z.; Hou, J.; Tyagi, R.; Liang, Y.; Hu, Y. Purification and characterization of a novel, highly potent fibrinolytic enzyme from Bacillus subtilis DC27 screened from Douchi, a traditional Chinese fermented soybean food. Sci. Rep. 2019, 9, 9235. [CrossRef] [PubMed]

3. Mackman, N.; Bergmeier, W.; Stouffer, G.A.; Weitz, J.I. Therapeutic strategies for thrombosis: New targets and approaches. Nat. Rev. Drug Discov. 2020, 19, 333-352. [CrossRef] [PubMed]

4. World Health Organization. Cardiovascular Diseases Overview. Available online: https://www.who.int/health-topics/ cardiovascular-diseases /\#tab=tab_1 (accessed on 19 June 2021).

5. Sharma, C.; Salem, G.E.M.; Sharma, N.; Gautam, P.; Singh, R. Thrombolytic potential of novel thiol-dependent fibrinolytic protease from Bacillus cereus RSA1. Biomolecules 2020, 10, 3. [CrossRef]

6. Kotb, E. The biotechnological potential of fibrinolytic enzymes in the dissolution of endogenous blood thrombi. Biotechnol. Progr. 2014, 30, 656-672. [CrossRef]

7. Altaf, F.; Wu, S.; Kasim, V. Role of fibrinolytic enzymes in anti-thrombosis therapy. Front. Mol. Biosci. 2021, 8, 680397. [CrossRef] [PubMed]

8. Kotb, E.; Helal, G.E.D.A.; Edries, F.M. Screening for fibrinolytic filamentous fungi and enzymatic properties of the most potent producer, Aspergillus brasiliensis AUMC 9735. Biologia 2015, 70, 1565-1574. [CrossRef]

9. Cheng, G.; He, L.; Sun, Z.; Cui, Z.; Du, Y.; Kong, Y. Purification and biochemical characterization of a novel fibrinolytic enzyme from Streptomyces sp. P3. J. Microbiol. Biotechnol. 2015, 25, 1449-1459. [CrossRef] [PubMed]

10. Kotb, E. Microbial Fibrinolytic Enzyme Production and Applications. In Microbial Functional Foods and Nutraceuticals; John Wiley \& Sons Ltd.: Hoboken, NJ, USA, 2018. [CrossRef]

11. Páblo, E.C.S.; de Souza, F.A.S.D.; de Barros, R.C.; Marques, D.A.V.; Porto, A.L.F.; Bezerra, R.P. Enhanced production of fibrinolytic protease from microalgae Chlorella vulgaris using glycerol and corn steep liquor as nutrient. Ann. Microbiol. Res. 2017, 1, 9-19. [CrossRef]

12. Weng, Y.; Yao, J.; Sparks, S.; Wang, K.Y. Nattokinase: An oral antithrombotic agent for the prevention of cardiovascular disease. Int. J. Mol. Sci. 2017, 18, 523. [CrossRef]

13. Xu, J.; Du, M.; Yang, X.; Chen, Q.; Chen, H.; Lin, D.H. Thrombolytic effects in vivo of nattokinase in a carrageenan-induced rat model of thrombosis. Acta Haematol. 2014, 132, 247-253. [CrossRef] [PubMed]

14. Yuan, J.; Yang, J.; Zhuang, Z.; Yang, Y.; Lin, L.; Wang, S. Thrombolytic effects of Douchi Fibrinolytic enzyme from Bacillus subtilis LD-8547 in vitro and in vivo. BMC Biotechnol. 2012, 12, 36. [CrossRef] [PubMed]

15. Vijayaraghavan, P.; Arun, A.; Vincent, S.G.P.; Arasu, M.V.; Al-Dhabi, N.A. Cow dung is a novel feedstock for fibrinolytic enzyme production from newly isolated Bacillus sp. IND7 and its application in in vitro clot lysis. Front. Microbiol. 2016, 7, 361. [CrossRef]

16. Kotb, E. Activity assessment of microbial fibrinolytic enzymes. Appl. Microbiol. Biotechnol. 2013, 97, 6647-6665. [CrossRef]

17. Krishnamurthy, A.; Belur, P.D.; Subramanya, S.B. Methods available to assess therapeutic potential of fibrinolytic enzymes of microbial origin: A review. J. Anal. Sci. Technol. 2018, 9, 10. [CrossRef]

18. Mukherjee, A.K.; Rai, S.K.; Thakur, R.; Chattopadhyay, P.; Kar, S.K. Bafibrinase: A non-toxic, non-hemorrhagic, direct-acting fibrinolytic serine protease from Bacillus sp. strain AS-S20-I exhibits in vivo anticoagulant activity and thrombolytic potency. Biochimie 2012, 94, 1300-1308. [CrossRef] [PubMed]

19. Zaikina, N.A.; Shataeva, L.K.; Elinov, N.P.; Samsonov, G.V. Some properties of the protease from Aspergillus terricola. Mycopathologia 1975, 56, 153-157. [CrossRef]

20. Osmolovskiy, A.A.; Kreier, V.G.; Baranova, N.A.; Egorov, N.S. Properties of extracellular plasmin-like proteases of Aspergillus ochraceus micromycete. Appl. Biochem. Microbiol. 2017, 53, 429-434. [CrossRef]

21. Taneja, K.; Bajaj, B.K.; Kumar, S.; Dilbaghi, N. Production, purification and characterization of fibrinolytic enzyme from Serratia sp. KG-2-1 using optimized media. 3 Biotech 2017, 7, 184. [CrossRef]

22. Raju, E.V.N.; Divakar, G. An overview on microbial fibrinolytic proteases. Int. J. Pharm. Sci. Res. 2014, 5, 643-656. [CrossRef]

23. Krishnamurthy, A.; Belur, P.D. A novel fibrinolytic serine metalloprotease from the marine Serratia marcescens subsp. sakuensis: Purification and characterization. Int. J. Biol. Macromol. 2018, 112, 110-118. [CrossRef]

24. Sharma, C.; Nigam, A.; Singh, R. Computational-approach understanding the structure-function prophecy of Fibrinolytic Protease RFEA1 from Bacillus cereus RSA1. Peer] 2021, 9, e11570. [CrossRef]

25. Kim, S.B.; Lee, D.W.; Cheigh, C.I.; Choe, E.A.; Lee, S.J.; Hong, Y.H.; Choi, H.J.; Pyun, Y.R. Purification and characterization of a fibrinolytic subtilisin-like protease of Bacillus subtilis TP-6 from an Indonesian fermented soybean, Tempeh. J. Ind. Microbio. Biotech. 2006, 33, 436-444. [CrossRef] [PubMed]

26. Wei, X.; Luo, M.; Xu, L.; Zhang, Y.; Lin, X.; Kong, P.; Liu, H. Production of fibrinolytic enzyme from Bacillus amyloliquefaciens by fermentation of chickpeas, with the evaluation of the anticoagulant and antioxidant properties of chickpeas. J. Agr. Food Chem. 2011, 59, 3957-3963. [CrossRef] [PubMed] 
27. Kotb, E. Purification and partial characterization of serine fibrinolytic enzyme from Bacillus megaterium KSK-07 isolated from Kishk, a traditional Egyptian fermented food. Appl. Biochem. Micro. 2015, 51, 34-43. [CrossRef]

28. Bora, B.; Biswas, A.D.; Gurung, A.B.; Bhattacharjee, A.; Kumar, M.V.S.; Mukherjee, A.K. An in silico approach to understand the structure-function properties of a serine protease (Bacifrinase) from Bacillus cereus and experimental evidence to support the interaction of bacifrinase with fibrinogen and thrombin. J. Biomol. Struct. Dyn. 2016, 35, 622-644. [CrossRef] [PubMed]

29. Yao, Z.; Liu, X.; Shim, J.M.; Lee, K.W.; Kim, H.J.; Kim, J.H. Properties of a fibrinolytic enzyme secreted by Bacillus amyloliquefaciens RSB34, isolated from Doenjang. J. Microbiol. Biotech. 2017, 27, 9-18. [CrossRef]

30. Popova, E.A.; Kreyer, V.G.; Komarevtsev, S.K.; Shabunin, S.V.; Osmolovskiy, A.A. Properties of extracellular proteinase of the micromycete Aspergillus ustus 1 and its high activity during fibrillary-proteins hydrolysis. Appl. Biochem. Microbiol. 2021, 57, 200-205. [CrossRef]

31. Afini, A.V.M.; Sooraj, S.N.; Smitha, K.V.; Kunhi, A.A.M. Production and partial characterization of fibrinolytic enzyme from a soil isolate Aspergillus carbonarius S-CSR-0007. Int. J. Pharm. Pharm. Sci. 2016, 8, 142-148. [CrossRef]

32. Galiakberova, A.A.; Bednenko, D.M.; Kreyer, V.G.; Osmolovskiy, A.A.; Egorov, N.S. Formation and properties of extracellular proteinase of micromycete Aspergillus flavus O-1, active toward fibrillary proteins. Appl. Biochem. Microbiol. 2021, 57, 586-593.

33. Shilpa, H.K.; Ambekar, J.G.; Dongre, N.N.; Siddalingeshwara, K.G. Application of fibrinolytic enzyme from Aspergillus tamarii -In vitro studies. Eur. J. Pharm. Med. Res. 2019, 6, 560-562.

34. Yadav, S.; Siddalingeshwara, K.G. Biosynthesis of clot busting fibrinolytic enzyme from Aspergillus japonicum by supplementing carbon sources. Int. J. Curr. Microbiol. App. Sci. 2016, 5, 860-864. [CrossRef]

35. Banerjee, A.; Chisti, Y.; Banerjee, U.C. Streptokinase-A clinically useful thrombolytic agent. Biotechnol. Adv. 2004, 22, 287-307. [CrossRef]

36. Collen, D.; Lijnen, H.R.; Vanderschueren, S. Staphylokinase: Fibrinolytic properties and current experience in patients with occlusive arterial thrombosis. Verhandelingen-Koninklijke Academie Voor Geneeskunde van Belgie 1995, 57, $183-196$.

37. Choi, N.S.; Chang, K.T.; Maeng, P.J.; Kim, S.H. Cloning, expression and fibrin (ogen) olytic properties of a Subtilisn DJ-4 gene from Bacillus sp. DJ-4. FEMS Microbiol. Lett. 2004, 236, 325-331. [CrossRef]

38. Liu, X.; Kopparapu, N.K.; Li, Y.; Deng, Y.; Zheng, X. Biochemical characterization of a novel fibrinolytic enzyme from Cordyceps militaris. Int. J. Biol. Macromol. 2017, 94, 793-801. [CrossRef] [PubMed]

39. Lee, S.Y.; Kim, J.S.; Kim, J.E.; Sapkota, K.; Shen, M.H.; Kim, S.; Chun, H.S.; Yoo, J.C.; Choi, H.S.; Kim, M.K.; et al. Purification and characterization of fibrinolytic enzyme from cultured mycelia of Armillaria mellea. Protein Expr. Purif. 2005, 43, 10-17. [CrossRef] [PubMed]

40. Babu, V.; Devi, C.S. Exploring the in vitro thrombolytic potential of streptokinase-producing $\beta$-hemolytic Streptococci isolated from bovine milk. J. Gen. Appl. Microbiol. 2015, 61, 139-146. [CrossRef] [PubMed]

41. Collen, D. Staphylokinase: A potent, uniquely fibrin-selective thrombolytic agent. Nat. Med. 1998, 4, 279-284. [CrossRef]

42. Kim, W.; Choi, K.; Kim, Y.; Park, H.; Choi, J.; Lee, Y.; Oh, H.; Kwon, I.; Lee, S. Purification and characterization of a fibrinolytic enzyme produced from Bacillus sp. strain CK 11-4 screened from Chungkook-Jang. Appl. Environ. Microbiol. 1996, 62, $2482-2488$. [CrossRef]

43. Devaraj, Y.; Rajender, S.K.; Halami, P.M. Purification and characterization of fibrinolytic protease from Bacillus amyloliquefaciens MCC2606 and analysis of fibrin degradation product by MS/MS. Prep. Biochem. Biotechnol. 2018, 48, 172-180. [CrossRef] [PubMed]

44. Peng, Y.; Huang, Q.; Zhang, R.H.; Zhang, Y.Z. Purification and characterization of a fibrinolytic enzyme produced by Bacillus amyloliquefaciens DC-4 screened from douchi, a traditional Chinese soybean food. Comp. Biochem. Physiol. B. Biochem. Mol. Biol. 2003, 134, 45-52. [CrossRef]

45. Choi, N.S.; Yoo, K.H.; Hahm, J.H.; Yoon, K.S.; Chang, K.T.; Hyun, B.H.; Pil, J.; Kim, S.H. Purification and characterization of a new peptidase, bacillopeptidase DJ-2, having fibrinolytic activity: Produces by Bacillus sp. DJ-2 from Doen-Jang. J. Microbiol. Biotechnol. 2005, 15, 72-79.

46. Kim, S.H.; Choi, N.S. Purification and characterization of subtilisin DJ-4 secreted by Bacillus sp. strain DJ-4 screened from Doen-Jang. Biosci. Biotechnol. Biochem. 2000, 64, 1722-1735. [CrossRef] [PubMed]

47. Kim, H.K.; Kim, G.T.; Kim, D.K.; Choi, W.A.; Park, S.H.; Jeong, Y.K.; Kong, I.S. Purification and characterization of a novel fibrinolytic enzyme from Bacillus sp. KA38 originated from fermented fish. J. Ferment. Bioeng. 1997, 84, 307-312. [CrossRef]

48. Afifah, D.N.; Sulchan, M.; Syah, D.; Yanti; Suhartono, M.T.; Kim, J.H. Purification and characterization of a fibrinolytic enzyme from Bacillus pumilus 2.g isolated from Gembus, an Indonesian fermented food. Prev. Nutr. Food Sci. 2014, 19, 213-219. [CrossRef] [PubMed]

49. Syahbanu, F.; Giriwono, P.E.; Tjandrawinata, R.R.; Suhartono, M.T. Molecular analysis of a fibrin-degrading enzyme from Bacillus subtilis K2 isolated from the Indonesian soybean-based fermented food moromi. Mol. Biol. Rep. 2020, 47, 8553-8563. [CrossRef]

50. Gupta, A.; Tiwari, S.K. Probiotic potential of Lactobacillus plantarum LD1 isolated from batter of Dosa, a South Indian fermented food. Probiotics Antimicrob. Proteins 2014, 6, 73-81. [CrossRef] [PubMed]

51. Tamang, J.P.; Shin, D.H.; Jung, S.J.; Chae, S.W. Functional properties of microorganisms in fermented foods. Front. Microbiol. 2016, 7, 578. [CrossRef] 
52. Da Silva, M.M.; Rocha, T.A.; de Moura, D.F.; Chagas, C.A.; de Aguiar Júnior, F.C.A.; da Silva Santos, N.P.; Da Silva Sobral, R.V.; do Nascimento, J.M.; Lima Leite, A.C.; Pastrana, L.; et al. Effect of acute exposure in swiss mice (Mus musculus) to a fibrinolytic protease produced by Mucor subtilissimus UCP 1262: An histomorphometric, genotoxic and cytological approach. Regul. Toxicol. Pharmacol. 2019, 103, 282-291. [CrossRef]

53. $\mathrm{Wu}, \mathrm{B} . ; \mathrm{Xu}, \mathrm{J}$. Antithrombotic effect of a novel protein from Fusarium sp. CPCC 480097 in a rat model of artery-vein bypass thrombosis. Pharm. Biol. 2012, 50, 866-870. [CrossRef]

54. Abdel-Fattah, A.F.; Ismail, A.S.; Saleh, S.A. Purification and properties of two fibrinolytic enzymes from Fusarium oxysporum N.R.C.1. Zentralblatt für Mikrobiologie 1993, 148, 123-128. [CrossRef]

55. El-Aassar, S.A. Production and properties of fibrinolytic enzyme in solid state cultures of Fusarium pallidoroseum. Biotechnol. Lett. 1995, 17, 943-948. [CrossRef]

56. Kim, H.C.; Choi, B.S.; Sapkota, K.; Kim, S.; Lee, H.J.; Yoo, J.C.; Kim, S.J. Purification and characterization of a novel, highly potent fibrinolytic enzyme from Paecilomyces tenuipes. Proc. Biochem. 2011, 46, 1545-1553. [CrossRef]

57. Nascimento, T.P.; Conniff, A.E.S.; Moura, J.A.S.; Batista, J.M.S.; Costa, R.M.P.B.; Porto, C.S.; Takaki, G.M.C.; Porto, T.S.; Porto, A.L.F. Protease from Mucor subtilissimus UCP 1262: Evaluation of several specific protease activities and purification of a fibrinolytic enzyme. An. Acad. Bras. Cienc. 2020, 92, e20200882. [CrossRef] [PubMed]

58. Xiao-Lan, L.; Lian-Xiang, D.; Fu-Ping, L.; Xi-Qun, Z.; Jing, X. Purification and characterization of a novel fibrinolytic enzyme from Rhizopus chinensis 12. Appl. Microbiol. Biotechnol. 2005, 67, 209-214. [CrossRef]

59. Ali, U.; Ibrahim, Z. Production and some properties of fibrinolytic enzyme from Rhizomucor miehei (Cooney \& Emerson) Schipper. J. Appl. Sci. Res. 2008, 4, 892-899.

60. Sharkova, T.S.; Kornienko, E.I.; Osmolovskii, A.A.; Kreier, V.G.; Baranova, N.A.; Egorov, N.S. Morphological and physiological properties of the micromycete arthrobotrys longa, a producer of longolytin, a proteolytic complex with a thrombolytic effect. Microbiology 2016, 85, 180-184. [CrossRef]

61. Sharkova, T.S.; Matveeva, E.O.; Kreier, V.G.; Osmolovskiy, A.A.; Kurakov, A.V.; Baranova, N.A.; Egorov, N.S. Production of proteinase-plasminogen activators by micromycete Tolypocladium inflatum k1. Appl. Biochem. Microbiol. 2016, 52, 31-35. [CrossRef]

62. Zhang, S.; Wang, Y.; Zhang, N.; Sun, Z.; Shi, Y.; Cao, X.; Wang, H. Purification and characterisation of a fibrinolytic enzyme from Rhizopus microsporus var. tuberosus. Food Technol. Biotechnol. 2015, 53, 243-248. [CrossRef] [PubMed]

63. Deng, Y.; Liu, X.; Katrolia, P.; Kopparapu, N.K.; Zheng, X. A dual-function chymotrypsin-like serine protease with plasminogen activation and fibrinolytic activities from the GRAS fungus, Neurospora sitophila. Int. J. Biol. Macromol. 2018, 109, 1338-1343. [CrossRef] [PubMed]

64. Kornienko, E.I.; Osmolovskiy, A.A.; Kreyer, V.G.; Baranova, N.A.; Kotova, I.B.; Egorov, N.S. Characteristics and properties of the complex of proteolytic enzymes of the thrombolytic action of the micromycete Sarocladium strictum. Appl. Biochem. Microbiol. 2021, 57, 57-64. [CrossRef]

65. Syahbanu, F.; Elisabeth, K.; Narwastu, P.; Giriwono, P.E.; Tjandrawinata, R.R.; Suhartono, M.T. Fibrinolytic bacteria of Indonesian fermented soybean: Preliminary study on enzyme activity and protein profile. Food Sci. Technol. Campinas 2020, 40 (Suppl. 2), 458-465. [CrossRef]

66. Che, Z.; Cao, X.; Chen, G.; Liang, Z. 2020. An effective combination of codon optimization, gene dosage, and process optimization for high-level production of fibrinolytic enzyme in Komagataella phaffii (Pichia pastoris). BMC Biotechnol. 2020, 20, 63. [CrossRef]

67. Lan, G.; Li, C.; He, L.; Zeng, X.; Zhu, Q. Effects of different strains and fermentation method on nattokinase activity, biogenic amines, and sensory characteristics of natto. J. Food Sci. Technol. 2020, 57, 4414-4423. [CrossRef]

68. Wu, R.; Chen, G.; Pan, S.; Zeng, J.; Liang, Z. Cost-effective fibrinolytic enzyme production by Bacillus subtilis WR350 using medium supplemented with corn steep powder and sucrose. Sci. Rep. 2019, 9, 6824. [CrossRef]

69. Sharma, D.; Shekhar, S.K.; Kumar, A.; Godheja, J. Isolation, characterization, production and purification of fibrinolytic enzyme nattokinase from Bacillus subtilis. J. Ind. Microbiol. Biotechnol. 2020, 11, 1768-1776. [CrossRef]

70. Verma, P.; Chatterjee, S.; Keziah, M.S.; Devi, S.C. Fibrinolytic protease from marine Streptomyces rubiginosus VITPSS1. Cardiovasc. Hematol. Agents Med. Chem. 2018, 16, 44-45. [CrossRef]

71. Dhamodharan, D.; Naine, J.S.; Keziah, M.S.; Devi, S.C. Novel fibrinolytic protease producing Streptomyces radiopugnans VITSD8 from marine sponges. Mar. Drugs 2019, 17, 164. [CrossRef]

72. Kim, C.; Ri, K.; Choe, S. A novel fibrinolytic enzymes from the Korean traditional fermented food-Jotgal: Purification and characterization. J. Food Biochem. 2020, 44, e13255. [CrossRef]

73. Vélez-Gómez, J.M.; Melchor-Moncada, J.J.; Veloza, L.A.; Sepúlveda-Arias, J.C. Purification and characterization of a metalloprotease produced by the C8 isolate of Serratia marcescens using silkworm pupae or casein as a protein source. Int. J. Biol. Macromol. 2019, 135, 97-105. [CrossRef] [PubMed]

74. Naveena, B.; Gopinath, K.P.; Sakthiselvan, P.; Partha, N. Enhanced production of thrombinase by Streptomyces venezuelae: Kinetic studies on growth and enzyme production of mutant strain. Bioresour. Technol. 2012, 111, 417-424. [CrossRef] [PubMed]

75. Nailufar, F.; Tjandrawinata, R.R.; Suhartono, M.T. Thrombus degradation by fibrinolytic enzyme of Stenotrophomonas sp. originated from Indonesian soybean-based fermented food on Wistar rats. Adv. Pharmacol. Sci. 2016, 2016, 4206908. [CrossRef] [PubMed]

76. Arshad, A.; Zia, M.A.; Asgher, M.; Joyia, F.A.; Arif, M. Enhanced production of streptokinase from Streptococcus agalactiae EBL-31 by response surface methodology. Pak. J. Pharm. Sci. 2018, 31, 1597-1602. 
77. Huy, D.N.A.; Hao, P.A.; Hung, P.V. Screening and identification of Bacillus sp. isolated from traditional Vietnamese soybeanfermented products for high fibrinolytic enzyme production. Int. Food Res. J. 2016, 23, 326-331.

78. Ko, J.H.; Yan, J.P.; Zhu, L.; Qi, Y.P. Identification of two novel fibrinolytic enzymes from Bacillus subtilis QK02. Physiol. C Toxicol. Pharmacol. 2004, 137, 65-74. [CrossRef] [PubMed]

79. Saxena, R.; Singh, R. MALDI-TOF MS and CD spectral analysis for identification and structure prediction of a purified, novel, organic solvent stable, fibrinolytic metalloprotease from Bacillus cereus B80. BioMed Res. Int. 2015, 2015, 527015. [CrossRef] [PubMed]

80. Katrolia, P.; Liu, X.; Zhao, Y.; Kopparapu, N.K.; Zheng, X. Gene cloning, expression and homology modeling of first fibrinolytic enzyme from mushroom (Cordyceps militaris). Int. J. Biol. Macromol. 2020, 146, 897-906. [CrossRef]

81. Meshram, V.; Saxena, S.; Paul, K.; Gupta, M.; Kapoor, N. Production, purification and characterisation of a potential fibrinolytic protease from Endophytic Xylaria curta by solid substrate fermentation. Appl. Biochem. Biotechnol. 2017, 181, 1496-1512. [CrossRef]

82. Choi, B.S.; Sapkota, K.; Choi, J.H.; Shin, C.H.; Kim, S.; Kim, S.J. Herinase: A novel bifunctional fibrinolytic protease from the monkey head mushroom Hericium erinaceum. Appl. Biochem. Biotechnol. 2013, 170, 609-622. [CrossRef] [PubMed]

83. Choi, J.H.; Kim, D.W.; Kim, S.; Kim, S.J. Purification and partial characterization of a fibrinolytic enzyme from the fruiting body of the medicinal and edible mushroom Pleurotus ferulae. Prep. Biochem. Biotechnol. 2017, 47, 539-546. [CrossRef] [PubMed]

84. Rovati, J.I.; Delgado, O.D.; Figueroa, L.I.; Fariña, J.I. A novel source of fibrinolytic activity: Bionectria sp., an unconventional enzyme-producing fungus isolated from Las Yungas rainforest (Tucumán, Argentina). World J. Microbiol. Biotechnol. 2010, 26, 55-62. [CrossRef]

85. Park, I.S.; Park, J.U.; Seo, M.J.; Kim, M.J.; Lee, H.H.; Kim, S.R.; Kang, B.W.; Choi, Y.H.; Joo, W.H.; Jeong, Y.K. Purification and biochemical characterization of a 17 kDa fibrinolytic enzyme from Schizophyllum commune. J. Microbiol. 2010, 48, 836-841. [CrossRef] [PubMed]

86. Batomunkueva, B.P.; Egorov, N.S. Isolation, purification and resolution of the extracellular proteinase complex of Aspergillus ochraceus 513 with fibrinolytic and anticoagulant activities. Microbiology 2001, 70, 519-522. [CrossRef]

87. Shirasaka, N.; Naitou, M.; Okamura, K.; Fukuta, Y.; Terashita, T.; Kusuda, M. Purification and characterization of a fibrinolytic protease from Aspergillus oryzae KSK-3. Mycoscience 2012, 53, 354-364. [CrossRef]

88. Du, L.X.; Liu, X.L.; Lu, F.P.; Xiao, J.; Zheng, X.Q. Characteristics of a new fibrinolytic enzyme produced from Rhizopus chinensis 12\#. Sheng Wu Gong Cheng Xue Bao 2005, 21, 323-327. [PubMed]

89. Albuquerque, W.; Nascimento, T.; Brandão-Costa, R.; Fernandes, T.; Porto, A. Static magnetic field effects on proteases with fibrinolytic activity produced by Mucor subtilissimus. Bioelectromagnetics 2017, 38, 109-120. [CrossRef]

90. Li, H.P.; Hu, Z.; Yuan, J.L.; Fan, H.D.; Chen, W.; Wang, S.J.; Zheng, S.S.; Zheng, Z.L.; Zou, G.L. A novel extracellular protease with fibrinolytic activity from the culture supernatant of Cordyceps sinensis: Purification and characterization. Phytother. Res. 2007, 21, 1234-1241. [CrossRef]

91. Lee, J.S.; Baik, H.S.; Park, S.S. Purification and characterization of two novel fibrinolytic proteases from mushroom, Fomitella fraxinea. J. Microbiol. Biotechnol. 2006, 16, 264-271.

92. Matsubara, K.; Hori, K.; Matsuura, Y.; Miyazawa, K. Purification and characterization of a fibrinolytic enzyme and identification of fibrinogen clotting enzyme in a marine green alga, Codium divaricatum. Comp. Biochem. Physiol. B Biochem. Mol. Biol. 2000, 125, 137-143. [CrossRef]

93. Matsubara, K.; Hori, K.; Matsuura, Y.; Miyazawa, K. A fibrinolytic enzyme from a marine green alga, Codium latum. Phytochemistry 1999, 52, 993-999. [CrossRef]

94. Matsubara, K.; Sumi, H.; Hori, K.; Miyazawa, K. Purification and characterization of two fibrinolytic enzymes from a marine green alga, Codium intricatum. Comp. Biochem. Physiol. Biochem. Mol. Biol. 1998, 119, 177-181. [CrossRef]

95. Sumi, H.; Nakajima, N.; Yatagai, C. A unique strong fibrinolytic enzyme (katsuwokinase) in skipjack "Shiokara," a Japanese traditional fermented food. Comp. Biochem. Physiol. B Biochem. Mol. Biol. 1995, 112, 543-547. [CrossRef]

96. Egorov, N.S.; Prianishnikova, N.I.; Al-Nuri, M.A.; Aslanian, R.R. Streptomyces spheroides M8-2 strain-A producer of extracellular proteolytic enzyme possessing fibrinolytic and thrombolytic action. Nauchnye Doki Vyss Shkoly Biol Nauki 1985, 1,77-81.

97. Abdel-Fattah, A.F.; Ismail, A.S. Purification and some properties of pure Cochliobolus lunatus fibrinolytic enzyme. Biotechnol. Bioeng. 1984, 26, 407-411. [CrossRef]

98. Egorov, N.S.; Kochetov, G.A.; Khaĭdarova, N.V. Isolation and properties of the fibrinolytic enzyme from the Actinomyces thermovulgaris cultural broth. Mikrobiologiia 1976, 45, 455-459. [PubMed]

99. Osmolovskiy, A.A.; Schmidt, L.; Orekhova, A.V.; Kreyer, V.G.; Baranova, N.A.; Egorov, N.S. Effect of proteinase from Aspergillus fumigatus on blood plasma proteins. Moscow Univ. Biol. Sci. Bull. 2021, 76, 71-76. [CrossRef]

100. Larcher, G.; Bouchara, J.P.; Annaix, V.; Symoens, F.; Chabasse, D.; Tronchin, G. Purification and characterization of a fibrinogenolytic serine proteinase from Aspergillus fumigatus culture filtrate. FEBS Lett. 1992, 308, 65-69. [CrossRef]

101. Chimbekujwo, K.I.; Ja'afaru, M.I.; Adeyemo, O.M. Purification, characterization and optimization conditions of protease produced by Aspergillus brasiliensis strain BCW2. Sci. Afr. 2020, 8, e00398. [CrossRef]

102. Hariharan, P.; Naik, C.; Sharma, A.V.; Singh, P.; Kumar, P.S. Isolation, production and purification of new thrombolytic enzyme from Cladosporium spp. Eur. J. Biotechnol. Biosci. 2018, 6, 01-04.

103. Sugimoto, S.; Fujii, T.; Morimiya, T.; Johdo, O.; Nakamura, T. The fibrinolytic activity of a novel protease derived from a tempeh producing fungus, Fusarium sp. BLB. Biosci. Biotechnol. Biochem. 2007, 71, 2184-2189. [CrossRef] [PubMed] 
104. Wu, B.; Wu, L.; Chen, D.; Yang, Z.; Luo, M. Purification and characterization of a novel fibrinolytic protease from Fusarium sp. CPCC 480097. J. Ind. Microbiol. Biotechnol. 2009, 36, 451-459. [CrossRef] [PubMed]

105. Chandrashekhar, N.; Hariharan, P. Production, purification and characterization of fibrinolytic protease from Fusarium spp. CSN-6 through solid-state fermentation. Int. J. Eng. Res. Technol. 2019, 8, 192-198.

106. Nascimento, T.P.; Sales, A.E.; Porto, T.S.; Costa, R.M.P.B.; Breydo, L.; Uversky, V.N.; Porto, A.L.F.; Converti, A. Purification, biochemical, and structural characterization of a novel fibrinolytic enzyme from Mucor subtilissimus UCP 1262. Bioprocess Biosyst. Eng. 2017, 40, 1209-1219. [CrossRef]

107. Tharwat, N.A. Purification and biochemical characterization of fibrinolytic enzyme produced by thermophilic fungus Oidiodendron flavum. Biotechnology 2006, 5, 160-165. [CrossRef]

108. Ahmad, M.S.; Noor, Z.M.; Ariffin, Z.Z. Isolation and identification fibrinolytic protease endophytic fungi from Hibiscus leaves in Shah Alam. Int. J. Biol. Biomol. Agric. Food. Biotech. Eng. 2014, 8, 1109-1112.

109. Baggio, L.M.; Panagio, L.A.; Gasparin, F.G.M.; Sartori, D.; Celligoi, M.A.P.C.; Baldo, C. Production of fibrinogenolytic and fibrinolytic enzymes by a strain of Penicillium sp. isolated from contaminated soil with industrial effluent. Acta Sci. Health Sci. 2019, 41, e40606. [CrossRef]

110. Larcher, G.; Cimon, B.; Symoens, F.; Tronchin, G.; Chabasse, D.; Bouchara, J.P. A 33 kDa serine proteinase from Scedosporium apiospermum. Biochem. J. 1996, 315, 119-126. [CrossRef] [PubMed]

111. Wong, S.L. Advances in the use of Bacillus subtilis for the expression and secretion of heterologous proteins. Curr. Opin. Biotechnol. 1995, 6, 517-522. [CrossRef]

112. Meng, D.; Dai, M.; Xu, B.L.; Zhao, Z.S.; Liang, X.; Wang, M.; Tang, X.F.; Tang, B. Maturation of fibrinolytic bacillopeptidase F involves both hetero- and autocatalytic processes. Appl. Environ. Microbiol. 2015, 82, 318-327. [CrossRef]

113. Xiao, L.; Zhang, R.H.; Peng, Y.; Zhang, Y.Z. Highly efficient gene expression of a fibrinolytic enzyme (subtilisin DFE) in Bacillus subtilis mediated by the promoter of $\alpha$-amylase gene from Bacillus amyloliquefaciens. Biotechnol. Lett. 2004, 26, 1365-1369. [CrossRef]

114. Peng, Y.; Yang, X.J.; Xiao, L.; Zhang, Y.Z. Cloning and expression of a fibrinolytic enzyme (subtilisin DFE) gene from Bacillus amyloliquefaciens DC-4 in Bacillus subtilis. Res. Microbiol. 2004, 155, 167-173. [CrossRef] [PubMed]

115. Jeong, S.J.; Kwon, G.H.; Chun, J.; Kim, J.S.; Park, C.S.; Kwon, D.Y.; Kim, J.H. Cloning of fibrinolytic enzyme gene from Bacillus subtilis isolated from Cheonggukjang and its expression in protease-deficient Bacillus subtilis strains. J. Microbiol. Biotechnol. 2007, $17,1018-1023$.

116. Nguyen, T.T.; Quyen, T.D.; Le, H.T. Cloning and enhancing production of a detergent- and organic-solvent-resistant nattokinase from Bacillus subtilis VTCC-DVN-12-01 by using an eight-protease-gene-deficient Bacillus subtilis WB800. Microb. Cell Factories 2013, 12, 79. [CrossRef]

117. Liu, B.Y.; Song, H.Y. Molecular cloning and expression of nattokinase gene in Bacillus subtilis. Acta Biochem. Biophys. Sin. 2002, 34, 338-340.

118. Chiang, C.J.; Chen, H.C.; Chao, Y.P.; Tzen, J.T.C. Efficient system of artificial oil bodies for functional expression and purification of recombinant nattokinase in Escherichia coli. J. Agri. Food Chem. 2005, 53, 4799-4804. [CrossRef]

119. Jeong, S.J.; Heo, K.; Park, J.Y.; Lee, K.W.; Park, J.Y.; Joo, S.H.; Kim, J.H. Characterization of AprE176, a fibrinolytic enzyme from Bacillus subtilis HK176. J. Microbiol. Biotechnol. 2015, 25, 89-97. [CrossRef]

120. Peng, Y.; Zhang, Y.Z. Cloning and expression in E. coli of coding sequence of the fibrinolytic enzyme mature peptide from Bacillus amyloliquefaciens DC-4. Chin. J. Appl. Environ. Biol. 2002, 8, 285-289.

121. Zhang, R.H.; Xiao, L.; Peng, Y.; Wang, H.Y.; Bai, F.; Zhang, Y.Z. Gene expression and characterization of a novel fibrinolytic enzyme (subtilisin DFE) in Escherichia coli. Lett. Appl. Microbiol. 2005, 41, 190-195. [CrossRef]

122. Ghasemi, Y.; Dabbagh, F.; Ghasemian, A. Cloning of a fibrinolytic enzyme (Subtilisin) gene from Bacillus subtilis in Escherichia coli. Mol. Biotechnol. 2012, 52, 1-7. [CrossRef]

123. Yao, Z.; Kim, J.A.; Kim, J.H. gene cloning, expression, and properties of a fibrinolytic enzyme secreted by Bacillus pumilus BS15 isolated from gul (Oyster) jeotgal. Biotechnol. Bioproc. Eng. 2018, 23, 293-301. [CrossRef]

124. Ahn, M.J.; Ku, H.J.; Lee, S.H.; Lee, J.H. Characterization of a novel fibrinolytic enzyme, BsfA, from Bacillus subtilis ZA400 in Kimchi reveals its pertinence to thrombosis treatment. J. Microbiol. Biotechnol. 2015, 25, 2090-2099. [CrossRef]

125. Lai, Y.P.; Huang, J.; Wang, L.F.; Li, J.; Wu, Z.R. A new approach to random mutagenesis in vitro. Biotechnol. Bioeng. 2004, 86, 622-627. [CrossRef] [PubMed]

126. Mohanasrinivasan, V.; Devi, C.S.; Biswas, R.; Paul, F.; Mitra, M.; Selvarajan, E.; Suganthi, V. Enhanced production of nattokinase from UV mutated Bacillus spp. Bangladesh J. Pharmacol. 2013, 8, 110-115. [CrossRef]

127. Venkatanagaraju, E.; Divakar, G. Bacillus cereus GD 55 strain improvement by physical and chemical mutagenesis for enhanced production of fibrinolytic protease. Int. J. Pharm. Sci. Res. 2013, 4, 81-93.

128. Yongjun, C.; Wei, B.; Shujun, J.; Meizhi, W.; Yan, J.; Yan, Y.; Zhongliang, Z.; Goulin, Z. Directed evolution improves the fibrinolytic activity of nattokinase from Bacillus natto. FEMS Microbiol. Lett. 2011, 325, 155-161. [CrossRef]

129. Sharma, A.; Sharma, A.; Shivlata, L. Optimization of medium components for enhanced production of extracellular fibrinolytic protease from Citrobacter braakii. Int. J. Curr. Microbiol. Appl. Sci. 2015, 4, 248-259. 
130. Vijayaraghavan, P.; Rajendran, P.; Prakash Vincent, S.G.; Arun, A.; Abdullah Al-Dhabi, N.; Valan Arasu, M.; Young Kwon, O.; Kim, Y.O. Novel sequential screening and enhanced production of fibrinolytic enzyme by Bacillus sp. IND12 using response surface methodology in solid-state fermentation. BioMed Res. Int. 2017, 2017, 3909657. [CrossRef]

131. Joji, K.; Santhiagu, A.; Salim, N. Computational modeling of culture media for enhanced production of fibrinolytic enzyme from marine bacterium Fictibacillus sp. strain SKA27 and in vitro evaluation of fibrinolytic activity. 3 Biotech 2019, 9, 323. [CrossRef]

132. Moharam, M.E.; El-Bendarya, M.A.; El-Beihb, F.; Easa, S.M.H.; Elsoud, M.M.A.; Azzam, M.I.; Elgamal, N.N. Optimization of fibrinolytic enzyme production by newly isolated Bacillus subtilis Egy using central composite design. Biocatal. Agric. Biotechnol. 2019, 17, 43-50. [CrossRef]

133. Anusree, M.; Swapna, K.; Aguilar, C.N.; Sabu, A. Optimization of process parameters for the enhanced production of fibrinolytic enzyme by a newly isolated marine bacterium. Bioresour. Technol. Rep. 2020, 11, 100436. [CrossRef]

134. Chen, P.T.; Chiang, C.J.; Chao, Y.P. Medium optimization for the production of recombinant nattokinase by Bacillus subtilis using response surface methodology. Biotechnol. Prog. 2007, 23, 1327-1332. [CrossRef]

135. Duraikannu, D.; Chandrasekaran, S.D. Optimization and modeling studies on the production of a new fibrinolytic protease using Streptomyces radiopugnans_VITSD8. Front. Biol. 2018, 13, 70-77. [CrossRef]

136. Wang, J.K.; Chiu, H.H.; Hsieh, C.S. Optimization of the medium components by statistical experimental methods to enhance nattokinase activity. Fooyin J. Health Sci. 2009, 1, 21-27.

137. Suwanmanon, K.; Hsieh, P.C. Isolating Bacillus subtilis and optimizing its fermentative medium for GABA and nattokinase production. CyTA J. Food 2014, 12, 282-290. [CrossRef]

138. Mahajan, P.M.; Nayak, S.; Lele, S.S. Fibrinolytic enzyme from newly isolated marine bacterium Bacillus subtilis ICTF-1: Media optimization, purification and characterization. J. Biosci. Bioeng. 2011, 113, 307-314. [CrossRef]

139. Avhad, D.N.; Rathod, V.K. Ultrasound assisted production of a fibrinolytic enzyme in a bioreactor. Ultrason. Sonochem. 2015, 22, 257-264. [CrossRef] [PubMed]

140. Vijayaraghavan, P.; Prakash Vincent, S.G. A low cost fermentation medium for potential fibrinolytic enzyme production by a newly isolated marine bacterium, Shewanella sp. IND20. Biotechnol. Rep. 2015, 7, 135-142. [CrossRef] [PubMed]

141. Vijayaraghavan, P.; Vincent, S.G. Statistical optimization of fibrinolytic enzyme production by Pseudoalteromonas sp. IND11 using cow dung substrate by response surface methodology. SpringerPlus 2014, 3, 60. [CrossRef]

142. Osmolovskiy, A.A.; Baranova, N.A.; Kreier, V.G.; Kurakov, A.V.; Egorov, N.S. Solid-state and membrane-surface liquid cultures of micromycetes: Specific features of their development and enzyme production (a Review). Appl. Biochem. Microbiol. 2014, 50, 219-227. [CrossRef]

143. Osmolovsky, A.A.; Kreier, V.G.; Baranova, N.A.; Kurakov, A.V.; Egorov, N.S. Production of extracellular proteinases-Protein C activators of blood plasma-By the micromycete Aspergillus ochraceus during submerged and solid-state fermentation. Appl. Biochem. Microbiol. 2013, 49, 581-586. [CrossRef]

144. Osmolovskiy, A.A.; Popova, E.A.; Kreyer, V.G.; Baranova, N.A.; Egorov, N.S. Vermiculite as a new carrier for extracellular protease production by Aspergillus spp. under solid-state fermentation. Biotechnol. Rep. 2021, 29, e00576. [CrossRef]

145. Gopinath, S.M.; Suneetha, T.B.; Ashwini-Patil, G.M. Exploration of newer substrate for fibrinolytic enzyme production by solid-state fermentation using Penicillium chrysogenum SGAD12. J. Res. Biol. 2011, 1, 242-245.

146. El-Aassar, S.A.; El-Badry, H.M.; Abdel-Fattah, A.F. The biosynthesis of proteases with fibrinolytic activity in immobilized cultures of Penicillium chrysogenum H9. Appl. Microbiol. Biotechnol. 1990, 33, 26-30. [CrossRef]

147. Komarevtsev, S.K.; Timorshina, S.N.; Leontieva, M.R.; Shabunin, S.V.; Lobakova, E.S.; Osmolovskiy, A.A. Effect of immobilization of the micromycete Aspergillus ochraceus VKM-F4104D in polymeric carriers on the production of the fibrinolytic protease activator of blood plasma protein C. Appl. Biochem. Microbiol. 2021, 57, 475-480. [CrossRef]

148. Karagoz, P.; Mandair, R.; Manayil, J.C.; Lad, J.; Chong, K.; Kyriakou, G.; Lee, A.F.; Wilson, K.; Bill, R.M. Purification and immobilization of engineered glucose dehydrogenase: A new approach to producing gluconic acid from breadwaste. Biotechnol. Biofuels 2020, 13, 100. [CrossRef] [PubMed]

149. Chang, B.S.; Hershenson, S. Practical approaches to protein formulation development. In Rational Design of Stable Protein Formulations. Pharmaceutical Biotechnology; Carpenter, J.F., Manning, M.C., Eds.; Springer: Boston, MA, USA, 2002 ; Volume 13. [CrossRef]

150. Poernomo, A.T.; Isnaeni, P. Thrombolytic activity of fibrinolytic enzyme from black soybean Tempeh (Glycine Soja Sieb. Et Zucc) fermented by Rhizopus oligosporus FNCC 6010. RJPBCS 2017, 8, 1885-1896.

151. Osman, M.E.; Abd El-All, S.M.; Khalifa, S.Y.E. Characterization of fibrinolytic enzymes produced by the halophilic Streptomyces flaveolus and Streptomyces galtieri isolated from Wady El-Natron area in North Egypt. Med. J. Cairo Univ. 2019, 87, 2323-2332.

152. Strathmann, H. The use of membranes in downstream processing. Food Biotechnol. 1990, 4, 253-272. [CrossRef]

153. Flaschel, E.; Wandrey, C.; Kula, M.R. Ultrafiltration for the separation of biocatalysts. In Downstream Processing. Advances in Biochemical Engineering/Biotechnology; Springer: Berlin/Heidelberg, Germany, 1983; Volume 26. [CrossRef]

154. Bautista, J.; Chico, E.; Machado, A. Cell removal from fermentation broth by flocculation-sedimentation. Biotechnol. Lett. 1986, 8 , 315-318. [CrossRef]

155. Dubey, R.; Kumar, D.; Agrawala, T.; Pusp, P. Isolation, production, purification, assay and characterization of fibrinolytic enzymes (Nattokinase, Streptokinase and Urokinase) from bacterial sources. Afr. J. Biotechnol. 2011, 10, 1408-1420. [CrossRef] 
156. Gao, D.; Mei, L.H.; Sheng, Q.; Xu, J.; Lin, D.Q.; Yao, S.J. Separation and purification of nattokinase produced by bacillus subtilis with ammonium sulfate precipitation and chromatography. Gao Xiao Hua Xue Gong Cheng Xue Bao/J. Chem. Eng. Chin. Univ. 2006, 20, 63-67.

157. Sasmita, I.R.A.; Sutrisno, A.; Zubaidah, E.; Wardani, A.K. Purification and characterization of a fibrinolytic enzyme from tempeh bongkrek as an alternative of thrombolytic agents. IOP Conf. Ser. Earth Environ. Sci. 2018, 131, 012041. [CrossRef]

158. Salunke, A.S.; Kharat, A.S. Data on isolation and purification of fibrinolytic enzyme from Pseudomonas baetica SUHU25. Data Brief 2019, 26, 104369. [CrossRef]

159. Devi, C.S.; Mohanasrinivasan, V.; Sharma, P.; Das, D.; Vaishnavi, B.; Naine, S.J. Production, purification and stability studies on nattokinase: A therapeutic protein extracted from mutant Pseudomonas aeruginosa CMSS isolated from bovine milk. Int. J. Pept. Res. Ther. 2016, 22, 263-269. [CrossRef]

160. Raj, T.S.; Athimoolam, S.; Vijayaraghavan, P. Biosynthesis and characterization of a novel fibrinolytic alkaline serine protease from newly isolated Bacillus flexus BF12 for biomedical applications. Curr. Pharm. Biotechnol. 2021, 22, 706-717. [CrossRef]

161. Xin, X.; Ambati, R.R.; Cai, Z.; Lei, B. Development of universal purification protocols for fibrinolytic enzyme-producing $b a c i l l i$. CyTA J. Food 2019, 17, 112-120. [CrossRef]

162. Chang, C.T.; Wang, P.M.; Hung, Y.F.; Chung, Y. Purification and biochemical properties of a fibrinolytic enzyme from Bacillus subtilis-fermented red bean. Food Chem. 2012, 133, 1611-1617. [CrossRef]

163. Kim, J.S.; Kim, J.E.; Choi, B.S.; Park, S.E.; Sapkota, K.; Kim, S.; Lee, H.H.; Kim, C.S.; Park, Y.; Kim, M.K.; et al. Purification and characterization of fibrinolytic metalloprotease from Perenniporia fraxinea mycelia. Mycol. Res. 2008, 112, 990-998. [CrossRef]

164. Vijayaraghavan, P.; Raj, S.R.F.; Vincent, S.G.P. Purification and characterization of fibrinolytic enzyme from Pseudoalteromonas sp., IND11 and its in vitro activity on blood clot. Int. J. Biol. Chem. 2015, 9, 11-20. [CrossRef]

165. Perez, N.; Urrutia, E.; Camino, J.; Orta, D.; Torres, Y.; Martinez, Y.; Cruz, M.; Alburquerque, S.; Gil, M.R.; Hernández, L. Hydrophobic interaction chromatography applied to purification of recombinant streptokinase. Minerva Biotecnologica 1998, 10, 174-177.

166. Liu, X.L.; Zheng, X.Q.; Qian, P.Z.; Kopparapu, N.K.; Deng, Y.P.; Nonaka, M.; Harada, N. Purification and characterization of a novel fibrinolytic enzyme from culture supernatant of Pleurotus ostreatus. J. Microbiol. Biotechnol. 2014, 24, 245-253. [CrossRef] [PubMed]

167. Rajaselvam, J.; Benit, N.; Alotaibi, S.S.; Rathi, M.A.; Srigopalram, S.; Biji, G.D.; Vijayaraghavan, P. In vitro fibrinolytic activity of an enzyme purified from Bacillus amyloliquefaciens strain KJ10 isolated from soybean paste. Saudi J. Biol. Sci. 2021, 28, 4117-4123. [CrossRef] [PubMed]

168. Komarevtsev, S.K.; Popova, E.A.; Kreyer, V.G.; Miroshnikov, K.A.; Osmolovskiy, A.A. Purification of the protease activator of protein c of human blood plasma produced by the micromycete Aspergillus ochraceus VKM F-4104D. Appl. Biochem. Microbiol. 2020, 56, 32-36. [CrossRef]

169. Rathnasamy, S.K.; Durai, A.; Vigneshkumar, A.A.; Purushothaman, C.; Rajendran, D.S.; Chandramouliswaran, K. One-pot simultaneous production and sustainable purification of fibrinolytic protease from Bacillus cereus using natural deep eutectic solvents. Sci. Rep. 2020, 10, 13356. [CrossRef] [PubMed]

170. Osmolovskiy, A.A.; Zvonareva, E.S.; Kreyer, V.G.; Baranova, N.A.; Egorov, N.S. The effects of micromycete extracellular proteases of the Aspergillus Genus on the proteins of the haemostatic system. Russ. J. Bioorganic Chem. 2014, 40, 634-639. [CrossRef]

171. Liu, J.G.; Xing, J.M.; Chang, T.S.; Liu, H.Z. Purification of nattokinase by reverse micelles extraction from fermentation broth: Effect of temperature and phase volume ratio. Bioprocess Biosyst. Eng. 2006, 28, 267-273. [CrossRef] [PubMed]

172. Nascimento, T.P.; Sales, A.E.; Porto, C.S.; Brandão, R.M.; de Campos-Takaki, G.M.; Teixeira, J.A.; Porto, T.S.; Porto, A.L.; Converti, A. Purification of a fibrinolytic protease from Mucor subtilissimus UCP 1262 by aqueous two-phase systems (PEG/sulfate). J. Chromatogr. B Analyt. Technol. Biomed. Life Sci. 2016, 1025, 16-24. [CrossRef]

173. Ashipala, O.K.; He, Q. Optimization of fibrinolytic enzyme production by Bacillus subtilis DC-2 in aqueous two-phase system (poly-ethylene glycol 4000 and sodium sulfate). Bioresour. Technol. 2008, 99, 4112-4119. [CrossRef] [PubMed]

174. Taneja, K.; Bajaj, B.; Kumar, S.; Dilbaghi, N. Process optimization for production and purification of novel fibrinolytic enzyme from Stenotrophomonas sp. KG-16-3. Biocatal. Biotransform. 2018, 37, 1-15. [CrossRef]

175. Al Farraj, D.A.; Kumar, T.S.J.; Vijayaraghavan, P.; Elshikh, M.S.; Alkufeidy, R.M.; Alkubaisi, N.A.; Alshammari, M.K. Enhanced production, purification and biochemical characterization of therapeutic potential fibrinolytic enzyme from a new Bacillus flexus from marine environment. J. King Saud Univ. Sci. 2020, 32, 3174-3180. [CrossRef]

176. Tsymanovich, S.A.; Nikandrov, V.N.; Maksimova, R.A.; Sharkova, T.S.; Andreenko, G.V.; Serebriakova, T.N. Fiziko-khimicheskie svoǐstva tromboliticheskogo preparata longolitina Physico-chemical properties of the thrombolytic compound longolytin. Voprosy Meditsinskoi Khimii 1992, 38, 44-45. [PubMed]

177. Park, S.E.; Li, M.H.; Kim, J.S.; Sapkota, K.; Kim, J.E.; Choi, B.S.; Yoon, Y.H.; Lee, J.C.; Lee, H.H.; Kim, C.S.; et al. Purification and characterization of a fibrinolytic protease from a culture supernatant of Flammulina velutipes mycelia. Biosci. Biotechnol. Biochem. 2007, 71, 2214-2222. [CrossRef] [PubMed]

178. Wong, A.H.; Mine, Y. Novel fibrinolytic enzyme in fermented shrimp paste, a traditional Asian fermented seasoning. J. Agric. Food Chem. 2004, 52, 980-986. [CrossRef] 
179. Choi, N.S.; Song, J.J.; Chung, D.M.; Kim, Y.J.; Maeng, P.J.; Kim, S.H. Purification and characterization of a novel thermoacid-stable fibrinolytic enzyme from Staphylococcus sp. strain AJ isolated from Korean salt-fermented Anchovy-joet. J. Ind. Microbiol. Biotechnol. 2009, 36, 417-426. [CrossRef]

180. Ueda, M.; Kubo, T.; Miyatake, K.; Nakamura, T. Purification and characterization of fibrinolytic alkaline protease from Fusarium sp. BLB. Appl. Microbiol. Biotechnol. 2007, 74, 331-338. [CrossRef]

181. Kumar, D.J.; Rakshitha, R.; Vidhya, M.A.; Jennifer, P.S.; Prasad, S.; Kumar, M.R.; Kalaichelvan, P.T. Production, optimization and characterization of fibrinolytic enzyme by Bacillus subtilis RJAS19. Pak. J. Biol. Sci. 2014, 17, 529-534. [CrossRef]

182. Yang, H.; Yang, L.; Li, X.; Li, H.; Tu, Z.; Wang, X. Genome sequencing, purification, and biochemical characterization of a strongly fibrinolytic enzyme from Bacillus amyloliquefaciens Jxnuwx-1 isolated from Chinese traditional Douchi. J. Gen. Appl. Microbiol. 2020, 66, 153-162. [CrossRef] [PubMed]

183. Lee, D.G.; Jeon, J.H.; Jang, M.K.; Kim, N.Y.; Lee, J.H.; Lee, J.H.; Kim, S.J.; Kim, G.D.; Lee, S.H. Screening and characterization of a novel fibrinolytic metalloprotease from a metagenomic library. Biotechnol. Lett. 2007, 29, 465. [CrossRef]

184. Cui, L.; Dong, M.S.; Chen, X.H.; Jiang, M.; Lv, X.; Yan, G. A novel fibrinolytic enzyme from Cordyceps militaris, a Chinese traditional medicinal mushroom. World J. Microbiol. Biotechnol. 2008, 24, 483-489. [CrossRef]

185. Lee, A.; Si-Kyung, A.; Bae, D.H.; Kwon, T.J.; Lee, S.B.; Lee, H.; Park, J.H.; Heo, S.; Johnson, M. Purification and characterization of a fibrinolytic enzyme from Bacillus sp. KDO-13 isolated from soybean paste. J. Microbiol. Biotechnol. 2001, 11, 845-852.

186. Lukianova, A.A.; Kornienko, E.I.; Vigand, P.A.; Kreyer, V.G.; Kurakov, A.V.; Osmolovskiy, A.A. Secretion by micromycetes of proteases with activity similar to the activity of the hemostatic system proteins. Moscow Univ. Biol. Sci. Bull. 2020, 75, 31-35. [CrossRef]

187. Kotb, E. The biotechnological potential of subtilisin-like fibrinolytic enzyme from a newly isolated Lactobacillus plantarum KSK-II in blood destaining and antimicrobials. Biotechnol. Prog. 2015, 31, 316-324. [CrossRef]

188. Ethiraj, S.; Gopinath, S. Production, purification, characterization, immobilization, and application of Serrapeptase: A review. Front. Biol. 2017, 12, 333-348. [CrossRef]

189. Wu, S.; Feng, C.; Zhong, J.; Huan, L. Roles of S3 site residues of Nattokinase on its activity and substrate specificity. J. Biochem. 2007, 142, 357-364. [CrossRef] [PubMed]

190. Chandrasekaran, S.D.; Vaithilingam, M.; Shanker, R.; Kumar, S.; Thiyur, S.; Babu, V.; Selvakumar, J.N.; Prakash, S. Exploring the in vitro thrombolytic activity of nattokinase from a new strain Pseudomonas aeruginosa CMSS. Jundishapur J. Microbiol. 2015, 8 , e23567. [CrossRef] [PubMed]

191. Agrebi, R.; Hmidet, N.; Hajji, M.; Ktari, N.; Haddar, A.; Fakhfakh-Zouari, N.; Nasri, M. Fibrinolytic serine protease isolation from Bacillus amyloliquefaciens An6 grown on Mirabilis jalapa tuber powders. Appl. Biochem. Biotechnol. 2010, 162, 75-88. [CrossRef] [PubMed]

192. Velusamy, P.; Pachaiappan, R.; Christopher, M.; Vaseeharan, B.; Anbu, P.; So, J.S. Isolation and identification of a novel fibrinolytic Bacillus tequilensis CWD-67 from dumping soils enriched with poultry wastes. J. Gen. Appl. Microbiol. 2015, 61, 241-247. [CrossRef]

193. Yeo, W.S.; Seo, M.J.; Kim, M.J.; Lee, H.H.; Kang, B.W.; Park, J.U.; Choi, Y.H.; Jeong, Y.K. Biochemical analysis of fibrinolytic enzyme purified from Bacillus subtilis strain A1. J. Microbiol. 2011, 49, 376-380. [CrossRef] [PubMed]

194. Jeong, Y.K.; Park, J.U.; Baek, H.; Park, S.H.; Kong, I.S.; Kim, D.W.; Joo, W.H. Purification and biochemical characterization of a fibrinolytic enzyme from Bacillus subtilis BK-17. World J. Microbiol. Biotechnol. 2001, 17, 89-92. [CrossRef]

195. Paik, H.D.; Lee, S.K.; Heo, S.; Kim, S.Y.; Lee, H.H.; Kwon, T.J. Purification and characterization of the fibrinolytic enzyme produced by Bacillus subtilis KCK-7 from Chungkookjang. J. Microbiol. Biotechnol. 2004, 14, 829-835.

196. Vijayaraghavan, P.; Prakash Vincent, S.G. Medium optimization for the production of fibrinolytic enzyme by Paenibacillus sp. IND8 using response surface methodology. Sci. World J. 2014, 3, 276942.

197. Wang, J.; Wang, M.; Wang, Y. Purification and characterization of a novel fibrinolytic enzymes from Streptomyces sp. Clin. J. Biotechnol. 1999, 15, 83-89.

198. Chitte, R.R.; Deshmukh, S.V.; Kanekar, P.P. Production, purification, and biochemical characterization of a fibrinolytic enzyme from thermophilic Streptomyces sp. MCMB-379. Appl. Biochem. Biotechnol. 2011, 165, 1406-1413. [CrossRef] [PubMed]

199. Narasimhan, M.K.; Ethiraj, S.; Krishnamurthi, T.; Rajesh, M. Purification, biochemical and thermal properties of fibrinolytic enzyme secreted by Bacillus cereus SRM-001. Prep. Biochem. Biotechnol. 2018, 48, 34-42. [CrossRef]

200. Biji, G.D.; Arun, A.; Muthulakshmi, E.; Vijayaraghavan, P.; Arasu, M.V.; Al-Dhabi, N.A. Bio-prospecting of cuttle fish waste and cow dung for the production of fibrinolytic enzyme from Bacillus cereus IND5 in solid state fermentation. 3 Biotech 2016, 6, 231. [CrossRef] [PubMed]

201. Meshram, V.; Saxena, S. Potential fibrinolytic activity of an endophytic Lasiodiplodia pseudotheobromae species. 3 Biotech 2016, 6 , 114. [CrossRef]

202. Abdel-Fattah, A.F.; Ismail, A.M. Preparation and properties of fibrinolytic enzymes produced by Cochliobolus lunatus. Biotechnol. Bioeng. 1984, 26, 37-40. [CrossRef]

203. Sanyanga, T.A.; Tastan-Bishop, Ö. Structural characterization of carbonic anhydrase VIII and effects of missense single nucleotide variations to protein structure and function. Int. J. Mol. Sci. 2020, 21, 2764. [CrossRef]

204. Frias, J.; Toubarro, D.; Fraga, A.; Botelho, C.; Teixeira, J.; Pedrosa, J.; Simões, N. Purification and characterization of a thrombolytic enzyme produced by a new strain of Bacillus subtilis. J. Microbiol. Biotechnol. 2021, 31, 327-337. [CrossRef] 
205. Zheng, Z.L.; Zuo, Z.Y.; Liu, Z.G.; Tsai, K.C.; Liu, A.F.; Zou, G.L. Construction of a 3D model of nattokinase, a novel fibrinolytic enzyme from Bacillus natto. A novel nucleophilic catalytic mechanism for nattokinase. J. Mol. Graph. Model. 2005, 23, 373-380. [CrossRef] [PubMed]

206. Yanagisawa, Y.; Chatake, T.; Chiba-Kamoshida, K.; Naito, S.; Ohsugi, T.; Sumi, H.; Yasuda, I.; Morimoto, Y. Purification, crystallization and preliminary $\mathrm{X}$-ray diffraction experiment of nattokinase from Bacillus subtilis natto. Acta Crystallogr. Sect. $F$ Struct. Biol. Cryst. Commun. 2010, 66, 1670-1673. [CrossRef]

207. Irajie, C.; Mohkam, M.; Nezafat, N.; Mohammadi, F.; Ghasemi, Y. In silico analysis of nattokinase from Bacillus subtilis sp natto. Int. J. Pharm. Clin. Res. 2017, 9, 286-292. [CrossRef]

208. Mohanasrinivasan, V.; Mohanapriya, A.; Potdar, S.; Chatterji, S.; Konne, S.; Kumari, S.; Keziah, S.M.; Devi, C.S. In vitro and in silico studies on fibrinolytic activity of nattokinase: A clot buster from Bacillus sp. Front. Biol. 2017, 12, 219-225. [CrossRef]

209. Ilich, A.; Bokarev, I.; Key, N.S. Global assays of fibrinolysis. Int. J. Lab. Hematol. 2017, 39, 441-447. [CrossRef]

210. Jespersen, J.; Astrup, T. A study of the fibrin plate assay of fibrinolytic agents. Optimal conditions, reproducibility and precision. Haemostasis 1983, 13, 301-315. [CrossRef]

211. Wolberg, A.S.; Gabriel, D.A.; Hoffman, M. Analyzing fibrin clot structure using a microplate reader. Blood Coagul. Fibrinolysis 2002, 13, 533-539. [CrossRef]

212. Marsh, N.A.; Gaffney, P.J. The rapid fibrin plate-A method for plasminogen activator assay. Thromb. Haemost. 1977, 38, 545-551. [CrossRef]

213. Smith, A.A.; Jacobson, L.J.; Miller, B.I.; Hathaway, W.E.; Manco-Johnson, M.J. A new euglobulin clot lysis assay for global fibrinolysis. Thromb. Res. 2003, 112, 329-337. [CrossRef]

214. Amiral, J.; Laroche, M.; Seghatchian, J. A new assay for global fibrinolysis capacity (GFC): Investigating a critical system regulating hemostasis and thrombosis and other extravascular functions. Transfus. Apher. Sci. 2018, 57, 118-126. [CrossRef]

215. Benes, J.; Zatloukal, J.; Kletecka, J. Viscoelastic methods of blood clotting assessment-A multidisciplinary review. Front. Med. 2015, 2, 62. [CrossRef]

216. Gidron, E.; Margalit, R.; Shalitin, Y. A rapid screening test for reduced fibrinolytic activity of plasma: Streptokinase activated lysis time. J. Clin. Path. 1978, 31, 54-57. [CrossRef] [PubMed]

217. Weng, M.; Deng, X.; Bao, W.; Zhu, L.; Wu, J.; Cai, Y.; Jia, Y.; Zheng, Z.; Zou, G. Improving the activity of the subtilisin nattokinase by site-directed mutagenesis and molecular dynamics simulation. Biochem. Biophys. Res. Commun. 2015, 465, 580-586. [CrossRef]

218. Fossum, S.; Hoem, N.O. Urokinase and non-urokinase fibrinolytic activity in protease-inhibitor-deprived plasma, assayed by a fibrin micro-plate method. Immunopharmacology 1996, 32, 119-121. [PubMed]

219. Boudjeltia, K.Z.; Cauchie, P.; Remacle, C.; Guillaume, M.; Brohée, D.; Hubert, J.L.; Vanhaeverbeek, M. A new device for measurement of fibrin clot lysis: Application to the euglobulin clot lysis time. BMC Biotechnol. 2002, 2, 8. [CrossRef]

220. Longstaff, C. Measuring fibrinolysis: From research to routine diagnostic assays. J. Thromb. Haemost. 2018, 16, 652-662. [CrossRef]

221. Schöchl, H.; Nienaber, U.; Hofer, G.; Voelckel, W.; Jambor, C.; Scharbert, G.; Kozek-Langenecker, S.; Solomon, C. Goal-directed coagulation management of major trauma patients using thromboelastometry (ROTEM)- guided administration of fibrinogen concentrate and prothrombin complex concentrate. Crit. Care 2010, 14, R55. [CrossRef]

222. Mou, Q.; Zhou, Q.; Liu, S. Blood clot parameters: Prejudgment of fibrinolysis in thromboelastography. Clin. Chim. Acta 2018, 479, 94-97. [CrossRef]

223. Hett, D.A.; Walker, D.; Pilkington, S.N.; Smith, D.C. Sonoclot analysis. Br. J. Anaesth. 1995, 75, 771-776. [CrossRef] [PubMed]

224. Bonnard, T.; Law, L.S.; Tennant, Z.; Hagemeyer, C.E. Development and validation of a high throughput whole blood thrombolysis plate assay. Sci. Rep. 2017, 7, 2346. [CrossRef]

225. Gunawan, S.T.; Kempe, K.; Bonnard, T.; Cui, J.; Alt, K.; Law, L.S.; Wang, X.; Westein, E.; Such, G.K.; Peter, K.; et al. Multifunctional thrombin-activatable polymer capsules for specific targeting to activated platelets. Adv. Mater. 2015, 27, 5153-5157. [CrossRef] [PubMed]

226. Bonnard, T.; Tennant, Z.; Niego, B.; Kanojia, R.; Alt, K.; Jagdale, S.; Law, L.S.; Rigby, S.; Medcalf, R.L.; Peter, K.; et al. Novel thrombolytic drug based on thrombin cleavable microplasminogen coupled to a single-chain antibody specific for activated GPIIb/IIIa. J. Am. Heart Assoc. 2017, 6, e004535. [CrossRef]

227. Olson, J.D.; Cunningham, M.T.; Higgins, R.A.; Eby, C.S.; Brandt, J.T. D-dimer simple test, tough problems. Arch. Pathol. Lab. Med. 2013, 137, 1030-1038. [CrossRef]

228. Mavromatis, B.H.; Kessler, C.M. D-dimer testing: The role of the clinical laboratory in the diagnosis of pulmonary embolism. J. Clin. Pathol. 2001, 54, 664-668. [CrossRef]

229. Wakai, A.; Gleeson, A.; Winter, D. Role of fibrin D-dimer testing in emergency medicine. Emerg. Med. J. 2003, 20, 319-325. [CrossRef] [PubMed]

230. Adam, S.S.; Key, N.S.; Greenberg, C.S. D-dimer antigen: Current concepts and future prospects. Blood 2009, $113,2878-2887$. [CrossRef]

231. Majumdar, S.; Chattopadhyay, P.; Mukherjee, A.K. In vivo anticoagulant and thrombolytic activities of a fibrinolytic serine protease (Brevithrombolase) with the k-carrageenan-induced rat tail thrombosis model. Clin. Appl. Thromb. Hemost. 2016, 22, 594-598. [CrossRef] [PubMed]

232. Simkhada, J.R.; Cho, S.S.; Mander, P.; Choi, Y.H.; Yoo, J.C. Purification, biochemical properties and antithrombotic effect of a novel Streptomyces enzyme on carrageenan-induced mice tail thrombosis model. Thromb. Res. 2012, 129, 176-182. [CrossRef] [PubMed] 
233. Yan, F.; Yan, J.; Sun, W.; Yao, L.; Wang, J.; Qi, Y.; Xu, H. Thrombolytic effect of Subtilisin QK on carrageenan induced thrombosis model in mice. J. Thromb. Thrombolysis 2009, 28, 444-448. [CrossRef]

234. Kamiya, S.; Hagimori, M.; Ogasawara, M.; Arakawa, M. In vivo evaluation method of the effect of nattokinase on carrageenaninduced tail thrombosis in a rat model. Acta Haematol. 2010, 124, 218-224. [CrossRef]

235. Barbeyron, T.; Michel, G.; Potin, P.; Henrissat, B.; Kloareg, B. Iota-Carrageenases constitute a novel family of glycoside hydrolases, unrelated to that of kappa-carrageenases. J. Biol. Chem. 2000, 275, 35499-35505. [CrossRef]

236. Bekemeier, H.; Hirschelmann, R.; Giessler, A.J. Carrageenin-induced thrombosis in rats and mice: A model for testing antithrombotic substances? Agents Actions 1985, 16, 446-451. [CrossRef]

237. Hagimori, M.; Kamiya, S.; Yamaguchi, Y.; Arakawa, M. Improving frequency of thrombosis by altering blood flow in the carrageenan-induced rat tail thrombosis model. Pharmacol. Res. 2009, 60, 320-323. [CrossRef] [PubMed]

238. An, Y.H.; Freidman, R.J. Animal Models in Orthopedic Research; CRC Press Press: Washington, DC, USA, 1998.

239. Eckly, A.; Hechler, B.; Freund, M.; Zerr, M.; Cazenave, J.P.; Lanza, F.; Mangin, P.H.; Gachet, C. Mechanisms underlying $\mathrm{FeCl}_{3}$-induced arterial thrombosis. J. Thromb. Haemost. 2011, 9, 779-789. [CrossRef]

240. Surin, W.R.; Prakash, P.; Barthwal, M.K.; Dikshit, M. Optimisation of ferric chloride induced thrombosis model in rats: Effect of anti-platelet and anti-coagulant drugs. J. Pharmacol. Toxicol. Methods 2009, 61, 287-291. [CrossRef] [PubMed]

241. Li, W.; McIntyre, T.M.; Silverstein, R.L. Ferric chloride-induced murine carotid arterial injury: A model of redox pathology. Redox Biol. 2013, 1, 50-55. [CrossRef]

242. Diaz, J.A.; Obi, A.T.; Myers, D.D., Jr.; Wrobleski, S.K.; Henke, P.K.; Mackman, N.; Wakefield, T.W. Critical review of mouse models of venous thrombosis. Arterioscler. Thromb. Vasc. Biol. 2012, 32, 556-562. [CrossRef]

243. Furie, B.; Furie, B.C. Thrombus formation in vivo. J. Clin. Invest. 2005, 115, 3355-3362. [CrossRef]

244. Westrick, R.J.; Winn, M.E.; Eitzman, D.T. Murine models of vascular thrombosis. Arterioscler. Thromb. Vasc. Biol. 2007, 27, 2079-2093. [CrossRef]

245. Fujita, M.; Hong, K.; Ito, Y.; Fujii, R.; Kariya, K.; Nishimuro, S. Thrombolytic effect of nattokinase on a chemically induced thrombosis model in rat. Biol. Pharm. Bull. 1995, 18, 1387-1391. [CrossRef] [PubMed]

246. Sumi, H.; Hamada, H.; Nakanishi, K.; Hiratani, H. Enhancement of the fibrinolytic activity in plasma by oral administration of nattokinase. Acta Haematol. 1990, 84, 139-143. [CrossRef]

247. Urano, T.; Ihara, H.; Umemura, K.; Suzuki, Y.; Oike, M.; Akita, S.; Tsukamoto, Y.; Suzuki, I.; Takada, A. The profibrinolytic enzyme Subtilisin Nat purified from Bacillus subtilis cleaves and inactivates plasminogen activator inhibitor type 1. J. Biol. Chem. 2001, 276, 24690-24696. [CrossRef]

248. Pan, X.; Liang, P.; Teng, L.; Ren, Y.; Peng, J.; Liu, W.; Yang, Y. Study on molecular mechanisms of nattokinase in pharmacological action based on label-free liquid chromatography-tandem mass spectrometry. Food Sci. Nutr. 2019, 7, 3185-3193. [CrossRef] [PubMed]

249. Kim, J.Y.; Gum, S.N.; Paik, J.K.; Lim, H.H.; Kim, K.C.; Ogasawara, K.; Inoue, K.; Park, S.; Jang, Y.; Lee, J.H. Effects of nattokinase on blood pressure: A randomized, controlled trial. Hypertens. Res. 2008, 31, 1583-1588. [CrossRef] [PubMed]

250. Fadl, N.N.; Ahmed, H.H.; Booles, H.F.; Sayed, A.H. Serrapeptase and nattokinase intervention for relieving Alzheimer's disease pathophysiology in rat model. Hum. Exp. Toxicol. 2013, 32, 721-735. [CrossRef]

251. Moriya, N.; Nakata, M.; Nakamura, M.; Takaoka, M.; Iwasa, S.; Kato, K.; Kakinuma, A. Intestinal absorption of serrapeptase (TSP) in rats. Biotechnol. Appl. Biochem. 1994, 20, 101-108. [PubMed]

252. Kotb, E. Fibrinolytic bacterial enzymes with thrombolytic activity. In Fibrinolytic Bacterial Enzymes with Thrombolytic Activity; Springer: Berlin/Heidelberg, Germany, 2012. [CrossRef]

253. Panagariya, A.; Sharma, A.K. A preliminary trial of serratiopeptidase in patients with carpal tunnel syndrome. J. Assoc. Physicians India 1999, 47, 1170-1172.

254. Majima, Y.; Inagaki, M.; Hirata, K.; Takeuchi, K.; Morishita, A.; Sakakura, Y. The effect of an orally administered proteolytic enzyme on the elasticity and viscosity of nasal mucus. Arch. Otorhinolaryngol. 1988, 44, 355-359. [CrossRef]

255. Bracale, G.; Selvetella, L. Clinical study of the efficacy of and tolerance to seaprose $S$ in inflammatory venous disease. Controlled study versus serratio-peptidase. Minerva Cardioangiol. 1996, 44, 515-524.

256. Esch, P.M.; Gerngross, H.; Fabian, A. Reduction of postoperative swelling. Objective measurement of swelling of the upper ankle joint in treatment with serrapeptase: A prospective study. Fortschritte der Medizin 1989, 107, 67-68.

257. Mazzone, A.; Catalani, M.; Costanzo, M.; Drusian, A.; Mandoli, A.; Russo, S.; Guarini, E.; Vesperini, G. Evaluation of Serratia peptidase in acute or chronic inflammation of otorhinolaryngology pathology: A multicentre, doubleblind, randomized trial versus placebo. J. Int. Med. Res. 1990, 18, 379-388. [CrossRef]

258. Mecikoglu, M.; Saygi, B.; Yildirim, Y.; Karadag-Saygi, E.; Ramadan, S.S.; Esemenli, T. The effect of proteolytic enzyme serratiopeptidase in the treatment of experimental implant-related infection. J. Bone Joint Surg. Am. 2006, 88, 1208-1214. [CrossRef] [PubMed]

259. Vicari, E.; La Vignera, S.; Battiato, C.; Arancio, A. Treatment with non-steroidal anti-inflammatory drugs in patients with amicrobial chronic prostato-vesiculitis: Transrectal ultrasound and seminal findings. Minerva Urol. Nefrol. 2005, 57, 53-59.

260. Kim, J.B.; Jung, W.H.; Ryu, J.M.; Lee, Y.J.; Jung, J.K.; Jang, H.W.; Kim, S.W. Identification of a fibrinolytic enzyme by Bacillus vallismortis and its potential as a bacteriolytic enzyme against Streptococcus mutans. Biotechnol. Lett. 2007, 29, 605-610. [CrossRef] [PubMed] 
261. Mine, Y.; Wong, A.H.K.; Jiang, B. Fibrinolytic enzymes in Asian traditional fermented foods. Food Res. Int. 2005, 38, 243-250. [CrossRef]

262. Zukaite, V.; Biziulevicius, G.A. Acceleration of hyaluronidase production in the course of batch cultivation of Clostridium perfringens can be achieved with bacteriolytic enzymes. Lett. Appl. Microbiol. 2000, 30, 203-206. [CrossRef] [PubMed]

263. Masschalck, B.; Michiels, C.W. Antimicrobial properties of lysozyme in relation to foodborne vegetative bacteria. Crit. Rev. Microbiol. 2003, 29, 191-214. [CrossRef]

264. Masilamani, R.; Natarajan, S. Molecular cloning, overexpression and characterization of a new thiol-dependent, alkaline serine protease with destaining function and fibrinolytic potential from Marinobacter aquaeolei MS2-1. Biologia 2015, 70, 1143-1149. [CrossRef] 